\title{
OBREROS, ARTESANOS, INTELECTUALES Y ACTIVIDAD POLITICO-SINDICAL. APROXIMACION BIOGRAFICA A UN PERFIL DE LOS PRIMEROS MILITANTES DEL MOVIMIENTO OBRERO ARGENTINO
}

\author{
RICARDO FALCON \\ DARIO MACOR ** \\ ALEJANDRA MONSERRAT ***
}

Este trabajo tiene su historia y esa historia tiene mucho que ver con la estructura y la lógica de su elaboración y por eso nos parece necesario exponerla brevemente. En 1978, Robert Paris, convocó a un grupo de jóvenes bistoriadores latinoamericanos, estudiantes de post-grado en la Ecole des Hautes Etudes, de París, para iniciar las investigaciones tendientes a plasmar un Diccionario Biográfico del Movimiento Obrero Latinoamericano. Algún tiempo después, en el seno de este grupo se constituyó una sección argentina que trabajó en el tema hasta mediados de 1984 y que estaba integrada por Edgardo Bilsky, Eduardo Bittloch, Ricardo Falcón, Bernardo Gallitelli y el propio Robert Paris.

El objetivo no era, como lo ha expuesto Robert Paris, "constituir una galería de hombres ilustres", sino por el contrario, como daba ejemplo el Dictionnaire biographique du mouvement ouvrier français, dirigido por Jean Maitron, encontrar lo que Jean Jaures denominaba la inmensa multitud de hombres que salen por fin de la oscuridad(1). El desafío no era únicamente el rescate de esos hombres olvidados, de anónimos militantes que contribuyen diariamente a "hacer la historia", sino saber también, en que medida esos centenares de biografías, podían darnos un perfil global, sino ya de "la clase obrera", al menos del "movimiento obrero".

En un texto de 1981 destinado a fundamentar teóricamente cl trabajo del Diccionario, Robert Paris advertia que de una opción como la antes expuesta, se deducían algunas cuestiones metodológicas de importancia. La fundamental: así concebido, el Diccionario estaba destinado a quedar inconcluso y siempre abicrto, a diferencia de la mayoría de los diccionarios históricos, que limitan sus objetivos a un número determinado de personajes destacados.(2)

El trabajo del diccionario sigue abierto, queda pendiente su publicación y, al menos, en el breve plazo, de un primer tomo sobre las épocas pioneras, y ha dado lugar a cerca de dos mil biografias, que no agotan todavía, por mucho, la totalidad de nombres de posible incorporación. De ese conjunto, hemos tomado 778 correspondientes al período 1860-1906, como base para este trabajo y que fueron realizadas por Eduardo

*CONICET/ Universidad Nacional de Rosario. ** Universidad Nacional del Litoral *** Consejo Investigaciones de la Universidad Nacional de Rosario 
Bittloch, Ricardo Falcón y Robert Paris. La mayoría son inéditas, aunque algunas de ellas ya han servido como un elemento importante en algunos trabajos que sobre el movimiento obrero argentino se han publicado en los últimos años.(3)

Nuestro objetivo es pues, aqui, cuantificar algunas de las informaciones fundamentales que se desprenden de esas biografias e interpretarlas, luego, intentando buscar ese "perfil global". El término "biografias" no está exento en este caso de ambigüedades. A veces son "verdaderas" biografias, que incluyen datos variados sobre la vida del militante y con una extensión que puede llegar hasta tres carillas dactilografiadas. Sin embargo, en promedio, no se desborda la media carilla y los datos disponibles son generalmente incompletos. En efecto, no en nuchos casos hemos podido llenar con una biografía todos los "casilleros". A veces, disponemos de información sobre la fecha de nacimiento, pero no de la llegada a Argentina; sabemos la profesión, pero no a ciencia cierta la nacionalidad; podemos afirmar que ha sido militante sindical, pero no conocemos con precisión el sindicato en que militaba; etc. etc. etc. Y tenemos también, no pocas biografias en las que sólo disponemos de una información: que fue deportado en 1902 en aplicación de la Ley de Residencia, o que fue miembro en tal año y, quizás, sólo ese año, de la Comisión Directiva de un sindicato. Pero, esa es, en realidad, la "verdadera" biografía de muchos de esos "oscuroshacedores de la historia". No descartamos, de todas maneras, que en algunos casos, futuras investigaciones puedan ayudarnos a completarlas. Sobre todo las que pueden hacerse en archivos extranjeros. En este sentido, el trabajo biográfico, ta mbién queda abierto.

Esta diversidad en el tipo de biografias disponibles, guarda una relación directa con el tipo de fuentes de las que dispone el historiador de lo biográfico y, particularmente, en el caso de los sectores populares y el movimiento obrero. Quizás, la principal fuente de la que se ha dispuesto es la de los periódicos sindicales, anarquistas, socialistas y otros. Las posibilidades que nos ofrece este tipo de fuentes son variadas. Un dato puede provenir de una crónica sobre un congreso sindical y de ella deducir -no sin riesgo- la profesión, el sindicato a que pertenecía y a veces también la filiación política. La noticia de una deportación o la denuncia de una persecución sufrida por un militante, suele darnos algunas informaciones de importancia. De los artículos analíticos o simples denuncias publicadas, de un militante en periódicos, se pueden obtener, a veces, algunos datos sobre su vida. Las listas de suscriptores de los periódicos a narquistas -cuando no se trata de seudónimos-también son una valiosa fuente de información. Las noticias necrológicas pueden proveernos de datos preciados sobre la vida de un militante. Las listas de delegados a los congresos partidarios o de federaciones obreras pueden constituir un buen punto de partida para comenzar a rastrear la vida de un militante. Igualmente, las listas de deportados y las crónicas policiales.

Los archivos -aunque escasos-tanto consulares como policiales, se convierten también en una fuente de singular valor. No obstante, cabe aquí una advertencia sobre la real efectividad de los archivos policiales, muy fuertemente teñidos por las pautas 
ideológicas de sus "archiveros" e informadores, que pueden despistamos, si pot ejemplo creemos, como en el caso francés, que Emilio Frugoni, figura máxima del socialismo uruguayo, era hacia 1917 , un "peligroso maximalista" actuando en Buenos Aires.

Sin embargo, este tipo de archivos es de acceso restringido. Generalmente existen interdicciones cronológicas sobre los períodos que pueden ser consultados. Es normal, que determinado archivo policial o diplomático no sea accesible al público antes de 50 o 30 años. De todas maneras las investigaciones realizadas en los archivos consulares franceses o en el "Archivio dello Stato" italiano, nos han sido particularmente útiles. También importantes son los archivos familiares, aunque de acceso todavía más difícil. Más de una vez, el temor de los descendientes a un "mal uso" de la memoria del antecesor, hace que esos archivos familiares queden en sótanos o en buhardilias y no siempre en las mejores condiciones. Existe, todavía, una dificultad adicional con los archivos argentinos: numerosas instituciones, entre ellas las cámaras patronales, las empresas y los sindicatos y aun los órganos del poder judicial -lo cual va más allá de lo "científico", sin duda-qucman sistemáticamente sus archivos cada diez años, al menos en muchos casos. Además, las persecuciones al movimiento obrero, han llevado a la pérdida de numerosos archivos. Las "menorias" o "autobiografias" de militantes son otra fuente importante. Abundante en datos, este tipo de producción literaria debe pasar necesariamente por el tamiz de la crítica del historiador, en la medida que puede incurrir en "auto-justificaciones" y "ajustes de cuentas". Lo mismo puede decirse de a lgunas "historias del movimiento obrero" como las que nos han legado Diego Abad de Santillán, Jacinto Oddone, Sebastián Marotta y otros. Finalmente, lo que podemos denominar "revistas de la época" nos dan, asinismo, informaciones valiosas.

Interroguémonos, ahora, sobre cuáles son los elementos que contribuyen a dotarnos de un "perfil" y que pueden ser deducidos de las biografías analizadas. La filiación política, la pertenencia sindical, la actividad profesional, la nacionalidad de origen, el tipo de militancia, su duración en el tiempo, si escribían o no en órganos propagandísticos, son todas ellas informaciones básicas de gran utilidad. A ellas deben sumarse las que provienen de informaciones "combinadas" producto de "cruzar" unos de esos tipos de datos con otros. Además, es necesario tener en cuenta, que esta clase de informaciones se nos ofrecen en proporciones bastante diferentes. En algunas, se alcanzan porcentajes superiores al $70 \%$, y en otras los datos disponibles oscilan en la mitad de lo posible. Tal como dijimos, casi nunca es factible llenar "todos los casilleros".

Lo antes dicho ya nos proporciona una idea primaria de lo que podemos saber y qué es lo que necesariamente seguiremos ignorando de ese conjunto de militantes. Muchos aspectos importantes de sus vidas quedarán irremediablemente en el olvido. Probablemente, nunca podremos reconstruir aspectos importantes de su vida familiar. Más aun, muchas cuestiones sobre las que disponemos de cientas informaeiones sólo nos darán un perfil parcial del conjunto de esos militantes, en la medida, 
que, a veces, resultan cuantitativamente insuficientes.

En consecuencia, admitimos, voluntariamente, los límites de los resultados de las investigaciones biográficas en las que nos hemos empeñado.

Por sí solas esas biografias no nos dirán demasiado del "perfil" buscado del movimiento obrero. No obstante, estas investigaciones biográficas combinadas con las que provienen, más en general, de la historia social, cultural o política, pueden constituir una contribución significativa.

Corresponde, ahora, explicitar cuales son las expectativas que pueden haber a nimado esta búsqueda investigativa biográfica para confrontarla, luego, con los resultados obtenidos. Finalmente, es posible reducir este conjunto de interrogantes a dos grandes problemáticas. El primer gra n interrogante que se nos presenta es: ¿cuál es ese tipo de militante predominante en la época, capaz de dedicar largas horas horas de su vida diaria a la militancia política, de saltar, a veces, de un continente a otro, de escribir artículos con lenguajes relativamente complejos sobre temas políticos y filosólicos; de mantener su actividad pese a reitcradas persecuciones?.

El segundo interrogante de peso deviene de preguntarnos acerca de las posibles determinaciones del tipo de prácticas políticas imperantes en el movimiento obrero de la época y su relación con lo que podríamos denomina "las ideologías predominantes". Más concretamente: , hasta dónde las condiciones étnicas y por nacionalidades extranjeras de origen, son determinantes de ciertas prácticas político-ideológicas corrientes en el período que estudiamos?

$Y$ finalmente, admitidas algunas de las variantes expuestas como explicaciones -si es que nos creemos en condición de hacerlo en forma definitivanos surge otro interrogante: ¿es posible fragmentar estas prácticas, metológicamente hablando, de manera que nos brinden "realidades parciales" susceptibles de ser integradas, luego, en una visión totalizadora o pretendidamente tal, al menos ?

Estos son algunos de los problemas fundamentales de los que trataremos de abordar en las páginas subsiguientes.

Veamos, ahora, la periodización que hemos adoptado para este trabajo. El punto de partida, 1860 , coincide con la aparición de las primeras sociedades mutuales estructuradas en torno a un oficio y una propaganda -sobre todo a través de periódicos y folletos- que globalmente podemos caracterizar como "socializante" y que admitia en su seno varios matices. Estos constituyen los antecedentes más lejanos, pero que inauguran un hilo conductor que ya no se corta, del movimiento obrero argentino. En realidad, hemos tomado la fecha de 1860 , para "redondear", porque la constitución de la Sociedad Tipográfica Bonaerense y de cuyos fundadores consignamos los nombres en nuestro trabajo, es de 1857.

Nos detenemos en 1906, porque creemos que alli se produce "un corte" que marca la aparición de una nueva generación militante. Admitimos que esa fecha no deja de presentar algunas dificultades. Probablemente, si no se tratara de un trabajo basado fundamentalmente en lo bjográfico, adoptaríamos como "corte", la más tradicional fecha de 1910. 
Pero, tenemos nuestras razones para aplicar aquí una periodización diferente. Creemos, coincidiendo con Abad de Santillán y laacov Oved, que en el caso del anarquismo, aparece después de la represión de 1902 y 1903, una nueva generación de militantes. A algunos de éstos los hemos consignados porque comvenzan a apa recer como milita ntes desde 1904. Pero, con las nuevas deportaciones que ocurren en 1905 , el cambio de generación se hace todavía más visible. Muchos militantes se van de la Argentina y otros ocupan su lugar.

En el caso del socialismo la situación es aun más clara. En ese año se produce la ruptura definitiva de la fracción de los futuros Sindicalistas Revolucionarios y aparece entonces, en el seno del movimiento obrero una nueva camada de militantes. Es cierto, que algunos de ellos ya venían militando desde las filas socialistas. Pero, lo hacían en general, como militantes de segundo plano, apenas detectables. En cambio, con la escisión pasarán a ocupar posiciones de primera línea. Y con la aparición del Sindicalismo Revolucionario se inaugurarán nuevos estilos de militancia.

Para algunos de los rubros que analizamos, hemos adoptado sub-períodos. La inclusión de uno u otro militante en un sub-período, está dada, en general, por la fecha más antigua de datos sobre su actividad en Argentina.

Hemos delineado tres subperíodos. El primero llega hasta 1881. El corte está dado también aquí, por la aparición, tanto de una nueva generación de militantes, como por un paralelo cambio en los estilos de militancia. En efecto, en 1882 se funda el club socialdemócrata alemán Vorwärts y poco después aparecen los primeros círculos propagandísticos anarco-comunistas. Ambos fenómenos marcan una diferencia con los tipos de militancia de los años 1870 , todavía muy marcados por la experiencia de la Primera Internacional. Además, desde los años ochenta se intensifica la actividad sindical, inaugurando también, nuevos estilos de militancia.

Entre 1881 y 1889 , fechas que marcan el segundo sub-período, se registran los mayores índices de incorporación de militantes. Un segundo corte, lo hemos establecido en 1899, porque inmediatamente después surgen las grandes federaciones obreras nacionales; comienza el período de las huelgas generales y de la adquisición de una particular virulencia en las luchas sociales, que marcan, también, nuevos estilos y nuevas situaciones.

\section{Perfil socio-profesional}

La tentativa de trazar un perfil socio-laboral de los primeros militantes del movimiento obrero en Argentina cuenta con un porcentaje relativamente alto de información disponible. En efecto, se tienen datos sobre actividad profesional en 554 casos sobre el total de 778 , es decir, el $71 \%$, mientras que los casos en los que no se tiene información son 224 , el $29 \%$. 


\section{Actividad Profesional}

\begin{tabular}{|c|c|c|c|}
\hline $\begin{array}{l}\text { Trabajadores } \\
\text { manuales }\end{array}$ & Intelectuales & Otros & Total \\
\hline$N^{\circ} \quad \%$ & $N^{2} \quad \%$ & $N^{2} \%$ & $N^{2}$ \\
\hline $476 \quad 86$ & $71 \quad 13$ & 7 & $554 \quad 100$ \\
\hline
\end{tabular}

La categoría "Trabajadores Manuales" incluye al conjunto de los oficios obreros o artesanales de la época y asimismo, como se verá más adelante, una cuota de trabajadores cuya profesión no ha sido posible discriminar. En "Intelectuales", utilizando el término, evidentemente, en un sentido lato, se han agrupado a todos los militantes que detentaban profesiones no manuales, tales como periodistas, profesionales liberales, docentes, artistas, etc. Y finalmente, "Otros", incluye algunos pocos casos que no pueden ser clasificados en ninguno de los otros dos rubros y que en su mayoría están relacionados con actividades comerciales. El cuadro precedente, revela, como era de esperar, una presencia mayoritaria de obreros y artesanos, pero también, la significativa existencia de un conjunto de militantes dedicados a actividades intelectuales y cuya extracción social, en la mayoría de los casos, puede presumirse vinculada a la naciente clase media urbana $\mathrm{o}$, incluso, en ciertas ocasiones, a los estratos más altos de la sociedad.

Dentro de los 224 casos en los que no se dispone información, encontramos básicamente, dos tipos de situaciones. Por una lado, en muchos de esos casos se disponen muy pocos datos como para determinar con precisión la actividad profesional. Por lo tanto podemos suponer que el número de "Trabajadores Manuales" puede ser mayor de Jo que se ha logrado determinar. Un ejemplo de esta situación es el de militantes desconocidos que figuran en las listas de deportados a causa de la Ley de Residencia.

El segundo tipo de situaciones está dado por la presencia de una cuota significativa de militantes bastante conocidos, especialmente en el caso de los anarquistas, pero, que aunque disponemos de numerosos datos sobre otros aspectos de sus vidas no se conoce la actividad profesional que desarrollaban. Esto es un producto de lo que denominamos "militancia profesional", es decir, militantes que en un comienzo tuvieron algún tipo de actividad laboral, pero que posteriormente se dedican de pleno a la agitación y a la propaganda, sosteniéndose con fondos destinados a financiar periódicos u otro lipo de actividades militantes, o que alternando con exilios y persecusiones, cambian de oficio frecuentemente.

Estos "militantes profesionales" evidencian un alto grado de movilidad laboral. Esto se percibe, incluso, en algunos casos de los que sí se dispone información. Hay biografias en las que son frecuentes los cambios de oficio. En esos casos de doble o múltiple actividad profesional se ha optado por aquella de mayor duración.

La movilidad profesional que se observa en un sector de militantes, especialmente anarquistas, como hemos dicho, se debe muchas veces a las 
persecuciones, tanto a las policiales, como a las que provienen de su inclusión en las "listas negras" de las orga nizaciones patronales, lo que les obligaba a cambiar de actividad.

\section{Trabajadores Manuales}

Sin discriminación de oficio

Con oficio

Total

\begin{tabular}{rr}
$\mathrm{N}^{\circ}$ & $\%$ \\
\hline 51 & 11 \\
425 & 89 \\
476 & 100
\end{tabular}

En el rubro "Sin discriminación de oficio"se han incluído los casos de titulares de biografias que por un conjunto de informaciones, debían sercomprendidos enire los trabajadores manuales, pero de los cuales no se tenían datos precisos sobre la rama de la actividad laboral en la cual se habían desempeñado. Este es el caso frecuente de militantes sindicales, de cuya actividad existen probadas referencias, pero que éstas no indican el oficio o profesión.

Trabajadores Manuales con oficio

Ferroviarios

Oficios de la construcción

Tipógrafos

Oficios de la madera

Panaderos

Metalúrgicos, mecánicos y otros

Zapateros

Constructores de carruajes

Portuarios y marítimos

Sastres

Oficios varios

TOTAL

\begin{tabular}{rr}
$\mathrm{N}^{\circ}$ & $\%$ \\
\hline 160 & 38 \\
48 & 11 \\
39 & 9 \\
37 & 9 \\
27 & 6 \\
25 & 6 \\
16 & 4 \\
13 & 3 \\
13 & 3 \\
8 & 2 \\
39 & 9 \\
476 & 100
\end{tabular}

Los rubros "Metalúrgicos, mecánicos y otros", "Oficios de la madera" y "Oficios de la construcción", se obtuvieron reagrupando oficios de un mismo sector de la actividad económica o con evidente afinidad entre sí. En el primero de ellos, se aglutinaron actividades como las de "herrero", "hojalatero", "fundidores", que suponían una cieria identidad común en el trabajo metalúrgico. En el segundo caso, se agruparon los de la industria de la madera, tales como ebanista,carpintero, escultor en madera, etc..Y en el tercero, un conjunto de profesiones obreras calificadas o artesanales relacionadas con la construcción: yeseros, albañiles, pintores, y otros. Lo 
mismo se hizo, en cierta medida con los trabajadores de artes gráficas, que en la época recibían la común denominación de tipógrafos, aunque, en realidad, incluían a éstos junto con otras actividades del ramo.

Estos agrupamientos no parecen arbitrarios ya que los propios militantes sindicales del período que nos ocupa, daban por sentado la común afinidad de ciertos oficios, lo que se revela, por lo menos en tres de los casos mencionados, de constitución en la primera década del siglo $\mathrm{XX}$, de federaciones, como las de la construcción, madera y gráficos, aunque las dos primeras fueran efímeras.

Si se exceptúan los casos de los ferroviarios y los portuarios, se puede concluir que una buena parte de los militantes pertenecían a los sectores de la actividad económica relacionada con el consumo local o en menor medida con actividades subsidiarias de la agro-exportación. En este sentido el perfil laboral parece corresponderse con el tipo de estructura ocupacional predominante en la época, más aun si se piensa, que en la mayoría de los casos se irata de militantes de medios urbanos.

Por otra parte, resulta evidente que la mayoría de los militantes de la época ejercían oficios obreros calificados e incluso en muchos casos con características artesanales. No podemos descartar que entre el $11 \%$ de trabajadores manuales cuyo oficio no ha podido discriminarse, haya alguna presencia de peones, jornaleros $u$ obreros sin calificación en general. Pero, de todas maneras ésta aparece en el periodo que estudiamos, claramente minoritaria.

Los porcentajes de pertenencia a los distintos oficios guardan relación no sólo con la estructura ocupacional de la época, como se ha dicho, sino también con las informaciones que se tienen sobre los gremios más activos sindicalmente. E] predominio de obreros calificados, se mantiene aun en el caso de los ferroviarios, ya que debe tenerse en cuenta, que la casi totalidad de los 160 militantes clasificados, pertenecían al sindicato "La Fraternidad" y de sus datos biográficos se desprende que en muy alta proporción eran maquinistas, foguistas o mecánicos.

Dos casos merecen especial atención: el de los tipógrafos y el de los ferroviarios. El porcentaje relativamente alto de presencia de los tipógrafos $(9 \%)$, revela una activa participación de un sector de trabajadores de ese gremio en la actividad política y sindical. Pero, si se tienen en cuenta las primeras épocas del movimiento obrero, la importancia de los tipógrafos aparece con mucho mayor fuerza. En efecto, entre 1860 y 1881 , los ípógrafos constituían un poco más del $40 \%$ del total de militantes registrados. Este porcentaje, se reduce, notablemente, en las tres décadas siguientes, aunque siguen manteniendo, como hemos visto, una presencia significativa.

El papel pionero desempeñado por los tipógrafos en la "prehistoria" del movimiento obrero argentino es conocido: en 1857 se funda la Sociedad Tipográfica Bonaerense, una de las primeras sociedades mutuales estructuradas en torno a un oficio y en todo caso la única que perdura rá de las que existían en esa época y lo hará durante muchas décadas. Hacia 1870 serán los tipógrafos los primeros militantes argentinos que establezcan contactos con la Asociación Internacional de Trabajadores y a fines de esa década protagonizarán con la Unión Tipográfica la primera huelga sostenida y 
organizada por una entidad con carácter sindical más o menos definido.

El papel pionero de los tipógrafos no es exclusivo de la Argentina, es -probablemente- universal y en todo casosin dudas latinoamericano. Desde épocas muy tempranas -desde los a ños cincuenta del siglo XIX-surgen también sociedades mutuales de tipógrafos en Brasil, Chile y Uruguay.

Este fenómeno no es arbitrario, si se tiene en cuenta, que los tipógrafos constituían una mano de obra altamente calificada. Saber leer y escribir era de por sí para un trabajador manual un grado de calificación alto. La conciencia de su especialización y de su "escasez" da tempranamente a los tipógrafos un fuerte espíritu de cuerpo y una profunda preocupación por la defensa y mejoramiento del "arte" que practicaban. Además, si se tiene en cuenta el caso argentino, es evidente que el hecho que la mayoría de los tipógrafos fueran hispanoamericanos -por obvias razonesfacilitaba una mejor integración corporativa, en momentos en que las tendencias de los trabajadores migrantes a aglutinarse por criterios étnico-linguísticos eran muy fuertes.

El segundo caso interesante es el de los ferroviarios, en los cuales puede sorprender a primera vista el alto porcentaje de militantes registrados: $38 \%$. Los ferroviarios y especialmente los que desde 1887 se reagrupan en "La Fraternidad" entidad sindical de maquinistas y foguisias de locomotoras que incluye también a mecánicos y otros calificados del riel, constituyen también un caso especial de espíritu corporativo y defensa profesional. No es casual, como se sabe, que "La Fraternidad" sea hoy, el más antiguo de los sindicatos existentes en Argentina y que haya mantenido una continuidad que supera los cien años.

Como se ha dicho muchas veces, los ferroviarios agrupados en "La Fraternidad" constituían una "élite", no sólo entre los trabajadores del sector sino también en el conjunto de los trabajadores argentinos de la época. Como los tipógrafos, eran trabajadores altamente calificados, pero, a diferencia de ellos, tenían una fuerza adicional: su número creciente, en una época de notoria expansión de la red ferroviaria y la conciencia que una huelga ferroviaria afectaba directamente el corazón de la economía de la agro-exportación.

El sindicato "La Fraternidad" constituirá un caso especial en el conjunto del sindicalismo argentino de la época. Es el primer sindicato en solicitar y obtener la personería jurídica,-y durante mucho tiempo el único en detentarla-sus estatutos preveen un papel "reformista" "legalista" de la entidad sindical -si se los compara con otros-y adopla medidas de fuerza, sólo, cuando se ha terminado el diálogo con las empresas. Ideológicamente, es diferente a la mayoría de los sindicatos. Y además, escapará, casi siempre, a las persecuciones que ellos sufren. La mayor continuidad y estabilidad, el fuerte espíritu corporativo y el apoliticismo declarado de "La Fraternidad", explican el alto número de militantes que bemos registrado y también, como veremos después, la mayor duración en el tiempo de sus dirigentes y militantes.

Todo lo dicho hasta aquí explica en buena medida -pero, sólo parcialmente-el hecho que los ferroviarios detenten un porcentaje de militantes sindicales superior, 
notoriamente, a la proporción de obreros del sector en el conjunto de la estructura ocupacional de la época. La segunda circunstancia explicativa tiene relación con los avatares del trabajo biográfico, la mayor estabilidad y continuidad comparativa de la "La fraternidad" ha facilitado que se gua rdaran los nombres de muchos militantes, que en el caso de otros sindicatos han quedado irremediablemente perdidos. Una prueba de ello, es que dos de sus militantes, Agnelli y Chitti hayan podido años después reconstruir una historia del sindicato, dejando en esas pá ginas los nombres de muchos de los pioneros(4). Lo mismo puede decirse, aunque en menor medida, para los tipógrafos. La continuidad -al menos a principio de siglo-de El Obrero Gráfico permilió a sus redactores rescatar nombres y momentos del período fundacional de la actividad mutualista y sindical del sector.

\section{Intelectuales.}

Escritores y periodistas.

Médicos.

Abogados.

Estudiantes.

Actores.

Varios.

TOTAL

\begin{tabular}{rr}
$N^{\circ}$ & $\%$ \\
\hline 21 & 30 \\
13 & 18 \\
10 & 14 \\
7 & 10 \\
7 & 10 \\
13 & 18 \\
71 & 100
\end{tabular}

Hemos agrupado en "Varios" a un conjunto de actividades correspondientes a profesiones liberales-ingenieros, arquitectos, contadores-y a docentes, que registraban bajos porcentajes, discriminando por rubro a las más significativas. Para la clasificación de "Escritores y periodistas" se tuvo en cuenta el hecho que se tratara de personas que tenían esta actividad como fuente de ingresos o que fuera la principal de sus actividades en el caso que hubieran tenido otra profesión colateral. Es decir, no hemos incluido en el rubro a los que no escribían profesionalmente sino que lo bacian sólo por razones políticas. Estos "escritores y periodistas políticos" serán considerados más adelante. Roberto Payró, Alberto Ghiraldo, Florencio Sánchez, son algunos de los nombres incluidos entre los "profesionales".

Si bien desde data muy temprana aparecen algunos pocos "intelectuales", la mayoría de estos militantes nos surgen durante la década del noventa y a principios de siglo. Esta "irrupción" de un núcleo significativo de intelectuales en el movimiento obrero es revelador de algunas transformaciones importantes que se estaban dando en la Argentina. Por un lado, expresa el proceso de conformación-aún incipiente-de una clase media urbana. $\mathrm{Y}$ al mismo tiempo, revela las dificultades que encontraban "los hijos" de esa recientemente constituida clase media urbana para acceder a ciertas posiciones -sobre todo universitarias y político/administrativasfrente a las restricciones que en ese sentido, significaba el "régimen oligá rquico". Es 
decir, que, paradójicamente, el acercamiento al movimiento obrero de algunos de esos intelectuales de clase media, está expresando las demandas másgenerales de esa nueva capa social que puja por obtener mayores márgenes de participación y representatividad en la sociedad.

Si nos detenemos brevemente en los nombres de algunos de esos intelectuales que se aproximan al movimiento obrero -Juan B. Justo, José Ingenieros, Roberto Pay ró, Alberto Ghiraldo, por ejemplo- podremos constatar que antes de acercarse al socialismo o al anarquismo, han pasado por la experiencia de la "Revolución del 90" -e incluso algunos, por la "revolución" radical de 1893- y que frente a la frustración momentánea sabemos hoy-de ese movimiento de reclamos democráticos, tornan su vista hacia el naciente movimiento obrero urbano.

La empresa no será vana. Y sobre todo en el caso de los que se acercan al socialismo. En buena medida, esos intelectuales se constituirán en miembros precla ros del partido y llegarán a imprimirle una nueva dirección.

Relativamente diferente, es el caso de los intelectuales de origen extranjero que en forma transitoria, o más o menos permanente, llegan a nuestras playas. Así, en los años ochenta, registramos un Winniger,-literato suizo-alemán-, según reza su biografia, o un Pietro Gori, -abogado, criminalista, italiano y a narquista- que durante algunos breves años sacude el incipiente mundo intelectual de Buenos Aires. Los intelectuales extranjeros son, generalmente, militantes perseguidos en su país de origen, que por algún tiempo se radican en Argentina.

Si dejamos de lado los "Escritores y periodistas" y tenemos en cuenta la suma de "Médicos" y "Abogados" -en conjunto el 32\%- nos encontramos con las dos profesiones "típicas" del período. Los primeros no sólo son representantes de una actividad humanilaria, digna y además rentable y apreciada, la de médico, sino que también aparecen entrelazados con la actividad científica más de "punta" en la época, la biología. En efecto, nos encontramos en la época de los éxitos de la pasterización -más de un biógrafo recordará el rol de Juan B.Justo, como uno de los introductores de la "esterilización" de instrumentos quirúrgicos en Argentina-y además, la presencia notoria de los médicos entre la pléyade de "higienistas", les concederá un papel predominante en la fusión entre "lo científico" y "lo social". Por lo tanto, no es de extrañar una proficua presencia de médicos en puestos dirigentes del movimiento obrero y en particular, entre los socia listas, como Manuel Ugarte, Juan B. Justo, Angel Giménez o Enrique Dickmann o, por ejemplo, Emilio Arana en el anarquismo.

La de abogacía era también una profesión de cierto prestigio intelectual,en la medida que en la época era la que preparaba para el "cursus honorum" de la política. Desde los años noventa, las carreras de abogacía y medicina se constituyen, crecientemente, en instrumentos de ascenso de las emergentes clases medias urbanas - sobre todo de sus "hijos"-al mismo tiempo que aseguran la posibilidad de una cierta "sensibilidad social" capaz de vincularlos con el naciente movimiento obrero.

La presencia de un cierto número de estudiantes vinculados tempranamente al movimiento obrero, es también un factor aseverador de esa disponibilidad de la 
emergente clase media - $\mathrm{ol}$ al menos, de algunos de sus componentes - para vincularse a ese nuevo actor social que surgía en la Argentina finisecular. Hemos computado como "estudiantes" a aquellos cuyo destino profesional ulterior ignoramos, eliminando de esta categoría a algunos estudiantes de los años noventa que después encontraremos clasificados como "profesionales", como son los casos, por ejemplo, de José Ingenieros y Nicanor Sarmiento.

También es importante la presencia de un pequeño porcentaje de "actores". Nos parece ineludible, confesar que ese porcentaje tiene también relación con los "avatares del historiador biográfico", $o$, al menos, en parte. En efecto, el acceso a un comentario de Caras y Caretas que sintetiza la actividad de los miembros del Grupo "El arte por la anarquía", más algunos rastreos hechos en periódicos anarquistas y socialistas sobre los protagonistas de algunos "cuadros filodramáticos" organizados por sociedades obreras del período, pueden aparecer inflando desmesuradamente la real proporción de "actores" entre los "intelectuales" vinculados al movimientos obrero. Sin embargo, nos anima la convicción que los actores constituían un elemento importante de esa cultura en formación del movimiento obrero, si es que se prefiere no hablar en términos de clase. Los actores y actrices constituían un elemento fundamental de esas representaciones "filo-dramámaticas" que acomıañaban las celebraciones significativas -tales como las de los aniversarios del $1^{\circ}$ de mayo-y que no sólo contribuían a la creación de un vínculo cultural perdurable en una capa social determinada, aunque heterogénea en su mezcla de obreros y artesanos, sino que también hacen figura creadora en la formación de algunos géneros literarios muy caros a la historia del teatro argentino, como el caso del "grotesco".

Otra observación que puede adquirir significación importante es la que deriva de advertir que -hasta cierto punto- estadísticamente es posible hacer alguna discriminación en las pertenencias en términos político-ideológicos, entre "profesiones liberales", por un lado, y "escritores y periodistas" y "artistas", por el otro. Aunque tanto, anarquistas y socialistas son encontrables en ambas categorías, es posible detectar una mayor presencia de los socialistas entre los "médicos" y "abogados" y una preferencia estadística similar de los anarquistas por las otras categorías antes expuestas. Sin demasiado riesgo interprefativo, se puede establecer vinculaciones entre estas tendencias estadísticas y las posiciones de uno y otro sector. En síntesis, las posturas "positivistas", "constructivas", de denuncia de la falta de representatividad política del régimen vigente, que ostentaban los socialistas, parecían tener mayores atractivos para los profesionales liberales -sobre todo médicos y abogadosque la actividad más denunciativa y crítica de los escritores y periodistas, donde tendríamos una mayor presencia de intelectuales anarquistas.

\section{La cuestión de la nacionalidad de los militantes}

Abordaremos, ahora, otra de las cuestiones que mayores divergencias de interpretación ha suscitado entre los historiadores. La pregunta es la siguiente: $¿$ basta 
dónde el perfil marcadamente migratorio y en consecuencia extranjero de las clases trabajadoras en Argentina, puede delinear las principales características del "movimiento obrero" tal cual hemos planteado precedentemente?. Una tentativa biográfica como la que ensayamos sólo puede darnos respuestas provisorias y no acabadas. En primer lugar, porque los datos que disponemos sobre la nacionalidad de los militantes son relativamente pocos. Así es: solamente en el $28,5 \%$ de los casos -220 sobre 778 -disponemos informaciones fidedignas sobre la nacionalidad de origen.

Argentinos y extranjeros

\begin{tabular}{|c|c|c|c|}
\hline \multicolumn{2}{|c|}{ Argentinos } & Extranjeros & Total \\
\hline & $\%$ & $\mathrm{~N}^{\circ} \%$ & $\mathrm{~N}^{\circ}$ \\
\hline & 18 & 180 & 220 \\
\hline
\end{tabular}

En el conjunto del período que hemos abordado es incuestionable el predominio de los militantes extra njeros sobre los a rgentinos, lo que parece corresponderse con las características generales -ampliamente conocidas-de la sociedad a rgentina de la época. Sin embargo, esta no es una tendencia que se mantenga incólume a lo largo de los distintos subperíodos que es posible establecer. Hasta 1881, no encontra mos a ningún argentino entre la lista de militantes. Lucgo, entre los que inician su militancia entre 1882 y 1889 , el porcentaje de argentinos se aproxima al $4 \%$, para llegar a casi un $9 \%$ en los primeros seis años del siglo XX.

La tendencia a que los argentinos-nacidos o naturalizados-adquirieran mayores porcentajes entre los militantes del movimiento obrero, a medida que avanzaban los años, parece incuestionable. Un poco más difícil es determinar cuántos eran "criollos" -es decir mestizos o descendientes hispánicos, previos al "boom" inmigratorio-y cuántos los hijos de inmigrantes. Los criterios censales de la época y la aplicación por la legislación argentina del principio del "jus soli", que asimilaba en la categoría de "nativos" a todos los nacidos en el territorio nacional, fueran o no descendientes de extranjeros, no nos permiten demasiado avanzar en deducciones comparativas. De todas maneras, se hace evidente un incremento de la participación de los argentinos en los registros de militantes, desde comienzos de la década del noventa.

Extranjeros por nacionalidad de origen

Italianos

Españoles

Franceses

Alemanes

Otros

TOTAL

\begin{tabular}{cc} 
N $^{2}$ & $\%$ \\
\hline 75 & 42 \\
50 & 28 \\
19 & 10,5 \\
22 & 12 \\
14 & 7,5 \\
180 & 100
\end{tabular}


A primera vista, la distribución de los porcentajes por orígenes nacionales se corresponde, aproximadamente, con las proporciones de extra njeros en el conjunto de la población, según los censos nacionales del período que nos ocupa. Sin embargo, encontramos algunas variantes importantes. $\mathrm{La}$ aseveración anterior parece ser cierta, sobre todo, para las proporciones de italianos y españoles. Pero, encontramos una distorsión cuando analizamos el porcentaje de militantes alemanes, que aparece como superior al de franceses, lo que contradice las proporciones de extranjeros por nacionalidad en el conjunto de la población.

Un segundo factor distorsionante aparece si analizamos estas proporciones de acuerdo a sub-períodos. Así, observamos, que algunos grupos por nacionalidad de origen son más significativos en ciertas épocas y otros en otras. Estas dos cuestiones nos introducen a una problemática - la de las oleadas de migraciones de carácter político- que está en la base del becho que los porcentajes de militantes por nacionalidad de origen no se corresponda, totalmente, con los extranjeros en el conjunto del país.

Una de las primeras oleadas de migrantes por causas políticas que registra la historia del movimiento obrero argentino, es la de los exiliados de la Comuna de París. Esto hace que en los años 1870 el porcentaje de militantes de origen francés sea relativamente elevado. Después, al calor de los indultos, estos militantes irán reingresando a su país de origen y su proporción disminuirá, favorecida también, por el progresivo declinio del conjunto de migrantes franceses. Muchos de los primeros militantes de la Asociación Internacional de Trabajadores -más conocida como Primera Internacional- fueron protagonistas de ese exilio provocado por el fracaso de la experiencia de la Comuna, aunque ya previamente desde 1848 y sobre todo desde 1851, las represiones políticas en Francia habían arrojado a tierras argentinas algunos militantes, intelectuales, de posterior renombre, como Amadeo Jaques y Alexis Peyret.

También, aunque posteriormente, en la década del 70, las represiones políticas en Italia y España, harán incrementar el número de emigrados políticos y en consecuencia el número de militantes de esas nacionalidades. Más fácilmente detectable será la llegada de numerosos militantes socialdemócratas alemanes -casi todos ellos fundadores o militantes del grupo socialista Vorwärts, con sede en Buenos Aires y Rosario- perseguidos por las leyes represivas bismarckianas. Como en los casos anteriores de franceses, italianos y españoles, esta emigración por causas políticas generará, temporariamente, alteraciones importantes en las proporciones de militantes registrados respecto a su comunidad de origen en el conjunto de los extranjeros en Argentina.

En la década del noventa la situación parece "normalizarse". Las migraciones políticas "abruptas" son menos frecuentes, al menos en un plano colectivo. Las proporciones de militantes extranjeros tienden a corresponderse en mayor medida con las de sus connacionales en el seno de la población del país. Un claro ejemplo de esto es el incremento del número de militantes españoles después de 1900 , que condice 
con un aumento relativo de los migrantes de ese país. Lo mismo puede decirse de la disminución relativa que para ese período registran los militantes italianos. Un último ejemplo de estas fluctuaciones en los flujos migratorios generales, es el de una mayor presencia esos años del rubro "Otros", que incluye nacionalidades varias, entre ellas, muchas de las que integran la "inmigración tardía" posterior a 1900 que comprende, ahora, a rusos, sirio-libaneses, eslavos en general, polacos, ctc..

Necesariamente una pregunta nos surge; ¿cuántos de estos militantes extranjeros vinieron al país ya portando su vocación política y sus ideas y cuántos comenzaron su actividad en Argentina?. Las respuestas no pueden ser sino tentativas e indicativas de tendencias, que además parecen variar según los sub-períodos. Del total de 180 extranjeros registrados y cuatro de igual indole, naturalizados argentinos, se dispone información sobre una posible militancia en el país de origen, en el $44 \%$ de los casos.

Militancia previa en el país de origen.

\begin{tabular}{cccccccc}
\hline \multicolumn{2}{c}{ SI } & \multicolumn{2}{c}{ NO } & \multicolumn{2}{c}{ Sin información } & \multicolumn{2}{c}{ Total } \\
\hline $\mathrm{N}^{\circ}$ & $\%$ & $\mathrm{~N}^{\circ}$ & $\%$ & $\mathrm{~N}^{\circ}$ & $\%$ & $\mathrm{~N}^{\circ}$ & $\%$ \\
\hline 76 & 41 & 7 & 3 & 101 & 56 & 184 & 100 \\
\hline
\end{tabular}

Las cifras expuestas parecieran corroborar el hecho que una mayoría de los extranjeros habían tenido experiencias militantes en su país de origen. Sin embargo, a esta creencia deben hacerse algunas observaciones restrictivas. En primer lugar, el porcentaje de casos sobre los cuales se tienen datos al respecto es suficientemente bajo, como para impedir generalizaciones apresuradas. Además, debe tenerse en cuenta que, en general se dispone de informaciones de este tipo en biografias de militantes bastante conocidos, en cambio no es posible determinarlo en el caso de los obreros menos conocidos. En segundo lugar, el alto número de biografías que no nos dan información al respecto, nos permite suponer que las tendencias pueden haber variado según las aliernativas cambiantes del marco más general que se desprende de los análisis y cuadros precedentes. Por lo tanto, es muy posible que en los años pioneros el número de militantes con actividad política previa fuera mayor que en los períodos posteriores, tal como lo revela la existencia de "oleadas" de migraciones por causas exclusivamente políticas.

\section{Tendencias políticas.}

Las informaciones que nos provienen de los datos sobre actividad profesional y orígenes por nacionalidad, pueden, todavía, proporcionarnos elementos importantes para el perfil global al que pretendemos aproximarnos. Pero, antes, parece necesario relacionarlos con los que nos provienen de la tendencia política de los 
militantes registrados. $Y$ para esto, debemos previamente incursionar en este terreno.

En este ámbito el porcentaje de casos con información al respecto es relativamente alto. En efecto, sobre los 778 militantes tenidos en cuenta, conocemos sus filiaciones políticas en 553 oportunidades, es decir, en el $71 \%$.

Militantes por tendencia política

\begin{tabular}{cccccccccc}
\hline \multicolumn{2}{l}{ Socialistas } & \multicolumn{2}{c}{ Anarquistas } & \multicolumn{3}{c}{ La Fraternidad } & \multicolumn{2}{c}{ Otros } & \multicolumn{2}{c}{ Total } \\
\hline $\mathrm{N}^{\circ}$ & $\%$ & $\mathrm{~N}^{\circ}$ & $\%$ & $\mathrm{~N}^{\circ}$ & $\%$ & $\mathrm{~N}^{\circ}$ & $\%$ & $\mathrm{~N}^{\circ}$ & $\%$ \\
\hline 186 & 34 & 194 & 35 & 157 & 22 & 16 & 3 & 553 & 100 \\
\hline
\end{tabular}

La inclusión de "Socialistas" y "Anarquistas" en el período que nos ocupa, aparece como más o menos obvia. Una explicación mayor merece la inclusión de "La Fraternidad" como una "tendencia politica" o "político sindical", si se prefiere. El primer dato justificativo de esta inclusión es el alto porcentaje de militantes de ese sindicato-recordemos: un $38 \%$ sobre el total con oficio-y si bien no podemos descartar que entre ellos haya algún anarquista o socialista, nada nos permite, por ahora, corroborarlo. El segundo elemento está dado por las características peculiares, ya descriptas, que presenta ese sindicato. Tanto por sus "tácticas", como por su "estrategia”, La Fraternidad, aun sin pretender constituirse en una corricnte político-sindical, aparecía como un sector diferenciado en el seno del movimiento obrero respecto a sus otros componentes. Esta diferencia era nétamente percibida por las otras tendencias y en particular por los otros sectores sindicales del mis mo gremio ferroviario. Zenón Cabral, militante de la Federación Obrera Ferrocarrilera, que agnupaba a sectores menos calificados del gremio, dirá años después, según consta en la biografía que elaborara Robert Paris, refiriéndose a los dirigentes de La Fraternidad: "eranhosiles a nuestro movimiento de clase. Kautsky diría que ellos son la aristocracia obrera".

El rubro "Otros" incluye, fundamentalmente a los militantes de las primeras épocas, particularmente, pero no exclusivamente, de la Primera Internacional, que no pueden ser englobados como "marxistas" ni "anarquistas", sino que muchas veces integran la amplia gama de lo que podría denominarse como cl "social-republicanismo" de la época. En otros casos y en períodos posteriores, el rubro incluye también a algunos pocos militantes "independientes" cuya definición política es difícil de deferminar o, finalmente, en algún caso, a posteriores militantes Sindicalistas Revolucionarios, cuyo paso previo por el Socialismo no aparece fidedignamente registrado. Es de presumir, también, que ciertos casos que aparecen como "Sin Información", podrían ser incluidos en este nubro "Otros".

Los "Sin Información", que no hemos integrado al cuadro precedente, incluyen dos tipos de situaciones. Por un lado, aquellos cuya filiación se ignora. Por oiro, un sector de independientes, militantes sindicales hacia 1901, en ocasión del primer congreso de la Federación Obrera Argentina -FOA-, que oscilaban entre las propuestas 
anarquistas y socialistas, y que después parecen haber optado -al menos, algunos de ellos-por las propuestas libertarias, aunque esto sea difícilmente corroborable en casos individuales.

Las cifras expuestas arrojan una casi paridad en el número de militantes anarquistas y socialistas. Habida cuenta de la existencia de casi un $30 \%$ de casos en los que no se dispone información, parece dificil hacer inferencias sobre ese dato. Es posible suponer que hasta, aproximadamente, 1901 el número de militantes anarquistas y socialistas, fuera parejo. Pero todo indica que después de 1902 y hasta -por lo menos1908 los anarquistas incrementan sus filas en mayor proporción. Además, por el tipo de militancia, es más fácil quealgunos militantes anarquistas queden en el olvido, que los socialistas.

La filiación política de los militantes que constan en las biografias que hemos podido confeccionar, revela un alto grado de estabilidad. Sin embargo, aparecen algunos "pases" de una tendencia a otra, aunque en casos extremadamente minoritarios. Los después notorios militantes socialistas, Gabriel Abad y Francisco Cúneo se inicia ron también en las filas anarquistas en los años noventa. El fenómeno inverso también se registra, como en el caso del militante rosarino Nicolás $R$. Blanco.

Más frecuentes son las conversiones de militantes republicanos o de grupos republicanos extranjeros, como los mazzinistas, hacia el socialismo o el anarquismo. Más que en el a narquismo, en el socialismo se registran numerosos casos de derivación hacia otras tendencias políticas, que tienen que ver con fenómenos colectivos. De esto, las dos grandes escisiones políticas que sufrió el socialismo argentino en las primeras décadas del siglo $\mathrm{XX}$, la de los Sindicalistas Revolucionarios de cuño soreliano, en 1906, y la de los Socialistas Internacionalistas, luego convertidos en Comunistas, a principios de 1918. Entre las biografias que hemos analizado existen varios casos de militantes socialistas que luego sufrirán alguna de estas mutaciones ideológicas. Sin embargo, son más frecuentes en el caso de los Sindicalistas Revolucionarios que en elde los Socialistas Internacionalistas, por una razón cronológica y generacional. No obstante, entre los casos analizados figuran algunos futuros fundadores o militantes importantes del Partido Comunista, como en el de José Penelón o de algunos miembros del Club Socialdemócrata alemán, Vorwärts, que en 1921, con la fracción "tercerista" ingresarian a las filas del leninismo.

Relación Tendencia Política-Actividad Profesional.

\begin{tabular}{lcccccccc}
\hline $\begin{array}{l}\text { Tendencia } \\
\text { Política }\end{array}$ & $\begin{array}{c}\text { Trabajadores } \\
\text { Manuales }\end{array}$ & \multicolumn{2}{c}{ Intelectuales } & \multicolumn{2}{c}{ Otros } & \multicolumn{2}{c}{ Total } \\
\hline Socialistas. & 88 & 71 & $N^{\circ}$ & $\%$ & $N^{\circ}$ & $\%$ & $N^{\circ}$ & $\%$ \\
Anarquistas. & 67 & 67,5 & 28 & 26,5 & 3 & 2,5 & 124 & 100 \\
La Fraternidad. & 154 & 98 & 3 & 28,5 & 4 & 4 & 99 & 100 \\
Otros. & 11 & 100 & - & - & - & - & 157 & 100 \\
\hline
\end{tabular}


Los 391 casos analizados en el cuadro precedente, corresponden al $50,5 \%$ del conjunto de los 778 militantes sobre los cuales se basa este trabajo, careciéndose de datos válidos en el restante $49,5 \%$. En principio, no pueden sacarse de él conclusiones demasiado importantes, sino es en el plano metodológico. En primer lugar, el hecho que los porcentajes de intelectuales sean más altos que los registrados en oportunidad de discriminar la actividad profesional sobre el conjunto de los militantes registrados, no nos permite conclusiones de fondo, sino que da una idea de las mayores dificultades para obtener este tipo de informaciones combinadas, como lo es la relación tendencia política-actividad profesional, entre trabajadores manuales respecto a los intelectuales. Las biografias de estos últimos suelen ser mucho más pródigas en informaciones que muchos de los primeros.

En segundo lugar, del hecho que de los militantes anarquistas registrados como trabajadores manuales haya porcentajes menores respecto a los socialistas sólo pueden extraerse conclusiones de orden similar a las anteriores. Por el tipo de actividad que realizan, por las mayores persecuciones a que estuvieron sometidos y por la estructura descentralizada del movimiento que protagonizaban, es más difícil obtener informaciones complejas de los anarquistas.

La proporción de trabajadores manuales en La Fraternidad resulta obvia. No obstante, es significativa la presencia de tres intelectuales "simpatizantes" del sindicato que colaboraban con sus actividades. Se trata de un ingeniero, un abogado y otro profesional que contribuían con las tareas de los dirigentes de La Fraternidad y que incluso, en algunos casos, llegaron a ocupar funciones "honorarias" en sus órganos directivos.

Más sugestivas parecen las informaciones combinadas que nos provienen de relacionar la tendencia política con la nacionalidad de origen de los militantes, aunque ahora, el porcentaje de los casos con informaciones disponibles sea menor. En efecto, solamente en 171 biografias, es decir el $22 \%$ del total, se ha podido establecer esa relación.

\section{Relación Nacionalidad- Tendencia Política Argentinos}

\begin{tabular}{|c|c|c|c|c|}
\hline \multirow[t]{2}{*}{ Tendencia Política } & Nacidos & \multicolumn{2}{|c|}{ Naturalizados } & Total \\
\hline & $\mathrm{N}^{\circ} \%$ & $\mathrm{~N}^{\circ}$ & $\%$ & $\mathrm{~N}^{\circ} \%$ \\
\hline Socialistas & $18 \quad 82$ & 4 & 18 & 22100 \\
\hline Anarquistas & 12100 & - & - & 12100 \\
\hline La Fraternidad & - - & - & - & - - \\
\hline Otros & 1100 & - & - & 1100 \\
\hline
\end{tabular}


Los socialistas detentan un mayor número de argentinos, tanto nativos como naturalizados. La diferencia sobre los a narquistas puede atribuirse, en el primer caso, a una mayor presencia de intelectuales de clase media, argentinos por nacimiento en buena parte. El segundo caso, el de los naturalizados, responde a la política socialista de hacer que sus afiliados extranjeros obtuvieran la ciudadanía para poder ejercer los derechos electorales.

Relación Nacionalidad-Tendencia política Extranjeros

\begin{tabular}{|c|c|c|c|c|c|c|c|c|c|c|}
\hline & \multicolumn{2}{|c|}{ Italianos } & \multicolumn{2}{|c|}{ Españoles } & \multicolumn{2}{|c|}{ Franceses } & \multicolumn{2}{|c|}{ Alemanes } & Otros & Total \\
\hline & $\mathrm{N}^{\circ}$ & $\%$ & $\mathrm{~N}^{\circ}$ & $\%$ & $\mathrm{~N}^{\circ}$ & $\%$ & $\mathrm{~N}^{\circ}$ & $\%$ & $\mathrm{~N}^{\circ} \%$ & $\mathrm{~N}^{\circ} \%$ \\
\hline Socialistas & 14 & 28 & 5 & 10 & 5 & 10 & 20 & 42 & 510 & 49100 \\
\hline Anarquistas & 38 & 49 & 26 & 34 & 9 & 12 & - & - & 45 & 77100 \\
\hline La Fraternidad & 1 & 33,3 & - & - & - & - & 1 & 33,3 & 133.3 & 3100 \\
\hline Otros & 1 & 14 & 2 & 28 & 4 & 58 & - & - & - & 7100 \\
\hline
\end{tabular}

Los socia listas revelan una mayoría de alemanes, luego, casi un $30 \%$ de italianos y una presencia minoritaria, repartida equitativamente, de españoles, franceses y nacionalidades varias. Los anarquistas registran una amplia mayoría de italianos y españoles, con una leve ventaja para los primeros, y $12 \%$ de franceses. El hecho que más de la mitad de los casos de esta última nacionalidad integren el rubro "Otros", se explica por la presencia de franceses, algunos de ellos exiliados de la Comuna en la primera época, en esa corriente que genéricamente hemos denominado "social-republicana".

Debe advertirse que la proporción de alemanes en el seno de las filas socialistas puede estar seguramente distorsionada, por el hecho que todos ellos eran militantes del grupo Vorwärss, y por lo tanto no ha sido difícil establecer su nacionalidad de origen. Es probable que entre los casos en los que tenemos información, haya un número mayor de socialistas italianos y, quizás, también españoles, del que hemos podido detectar. De todas maneras, es evidente, que sobre todo en la década del $80 \mathrm{y}$ parcialmente también en la primera mitad de la siguiente, la presencia de militantes alemanes fue de singular importancia en las filas socialistas.

Del cuadro precedente pueden extraerse algunas tendencias, ya que no conclusiones definitivas, dado el bajo porcentaje de informaciones obtenidas. Casi dos tercios de los militantes italianos son anarquistas; un poco más alta es la proporción de españoles de esa tendencia; entre los franceses representan la mitad y no hay ninguno entre los a lemanes. Los socialistas, registran más de un $40 \%$ de alema nes, casi un $30 \%$ de italianos y luego reparten sus preferencias entre las otras nacionalidades. 


\section{Los estilos de militancia.}

Podemos encontar dos tipos básicos de militantes en el período, aunque a veces a parezcan cruzados. Tenemos por un lado, los militantes sindicalistas y por otro, los que no cjercian actividad sindical y que estaban dedicados a tareas de agitación y propaganda. Esta distinción pudo hacerse en 662 casos, es decir el $85 \%$.

Tipo de militancia

\begin{tabular}{lcc}
\hline & $N^{\circ}$ & $\%$ \\
\hline Sindical & 425 & 64 \\
Nosindical & 237 & 46 \\
TOTAL & 662 & 100 \\
\hline
\end{tabular}

La existencia de una actividad de tipo sindical no excluye que se realicen actividades propagandísticas o de otro tipo. En realidad, debemos suponer que en varios casos, difícilmente cuantificables, se daba esta situación.

El cje central de la actividad propagandística eran los periódicos y scguramente también las "hojas volantes" u "hojas sueltas", aunque de este último tipo de texto tenemos pocos testimonios que hayan llegado hasta nosotros. En lo que concierne a los periodicos, estos tenían un papel central tanto en el socialismo cono en el anarquismo. Pero, en esta tendencia, dado su carácter descentralizado, el número de periódicosera muy extenso y en consecuencia amplio también el número de redactores y colaboradores episódicos.

Militantes que escribían en publicaciones.

\begin{tabular}{lrr} 
& $N^{2}$ & $\%$ \\
\hline Escribían & 241 & 31 \\
Sin información & 537 & 69 \\
TOTAL & 778 & 100 \\
\hline
\end{tabular}

Un porcentaje de militantes que escribian como el que surge del cuadro precedente es particularnente significativo si se piensa en las caracteristicas de la sociedad argentina de la época, con crecientes índices de analfabetismo, atribuibles, en gran parte, al incremento de la población extranjera.

Este desfase entre los grados de instrucción de la población y el relativamente alto porcentaje de militantes que escribian, nos remite-una vez más-a la idea que los militantes del movimiento obrero constituían, parcialmente, una especie de "élite" de obreros calificados, artesanos y algunos intelectuales. 


\section{Periódicos y publicaciones unitarias}

Escribían sólo en periódicos

Además en publicaciones unitarias TOTAL

\begin{tabular}{cc}
$\mathrm{N}^{\circ}$ & $\%$ \\
\hline 241 & 83,5 \\
46 & 16,5 \\
287 & 100
\end{tabular}

Denominamos publicaciones unitarias a lo que también sucle llamarse "obras", es decir escritos no periódicos, individuales o colectivos, generalmente libros o folletos. También en este caso tenemos la presunción que el número de los que practicaban este tipo de escritura era algo mayor de lo que hemos podido determinar. De todas maneras, un 16,5 revela, sobre una mayoría de militantes obreros y artesanos, un porcentaje bastante alto. Esto se sobredimensiona si se tiene en cuenta, que los autores de estas publicaciones unitarias no son únicamente intelectuales profesionales, sino que un cierto número de trabajadores o ex-trabajadores manuales, son productores de este tipo de literatura, particularmente "memorias", "relatos", "autobiografias", "ensayos" a "historias del movimiento obrero". Félix Basterra, Adrián Patroni, Sebastián Marotta, García Balsas, son responsables de este tipo de producciones, entre muchos otros.

Tomada en general, esa producción literaria de los militantes revela que cl género dominante es el ensayo político, volcado en libros y folletos. Las tesis universitarias son también otra de las formas en que se plasma esa literatura política. El caso más conocido es el de la tesis sobre la miseria elaborada por Alfredo Palacios, rechazada por el jurado y publicada de todas maneras, con el subtítulo de "tesis rechazada". Los temas preferenciales de estos ensayos y tesis están referidos en algunos casos a cuestiones político-filosóficas que suponen un cierto grado de abstracción. Sin embargo, mayoritariamente versan sobre análisis coyunturales de carácter político-social.

Otra de las cuestiones que hemos abordado es el de la duración de la actividad militante. Aquí, tampoco es fácil obtener informaciones para todos los casos. Son frecuentes las biografías que nos revela una militancia que comienza en la juventud y se prolonga hasta la muerte, la edad avanzada o la jubilación. Por otro lado, tenemos casos de militancia extremadamente corta, entre los cuales uno de los más notorios es el de Solitro, un anarquista que durante un año realiza una actividad incansable de propaganda, para desaparecer tan abruptamente como se había iniciado. Otras veces, militantes con trayectoria de cierta importancia abandonan repentinamente su lucha, como fue el caso de Gregorio Inglán Lafarga, figura prominenente del anarquismo finisecular, que después de ser perseguido durante la oleada represiva que siguió a la huelga general de 1902, se esconderá durante un largo tiempo, para no regresar después a las filas.

Como lo ha observado Diego Abad de Santillán, el problema de las militancias 
cortas se observaba con particular fuerza entre los anarquistas(5). Debemos suponer que este fenómeno debía registrarse no tanto en los dirigentes más consagrados, sino en lo que con un lenguaje de nuestros días llamaríamos "cuadros medios". El becho que sifuaciones de este tipo sean mucho menos frecuentes entre los socialistas, nos permite deducir que las deserciones guardan relación con las "expectativas" de corto plazo que inspiraban la acción revolucionaria de los militantes anarquistas.

En efecto, sobre todo después de 1895 , cuando se hace visible una reanimación del movimiento huelguístico que babía comenzado a manifestarse entre 1888 y 1890 , para decaer después como consecuencia de la crisis, y en particular después de la huelga general de 1902, surgen en el seno del anarquismo argentino, estrategias -sobre todo la de la huelga general insurreccional- que preconizaban una solución catastrófica revolucionaria que parecía iba a darse en no muy lejano plazo. La frustración de estas expectativas revolucionarias "cortoplacistas" parece haber actuado como un elemento que favorecía ciertas deserciones militantes. A esto, debe agregarse, que el anarquismo vivirá una situación constante de "semilegalidad", alternada con episodios de directa ilegalidad, durante los cuales las persecusiones, al menos el hostigamiento del Estado y los empresarios, era constante.

En los socialistas, en cambio, las expectativas de transformación social descansaban mucho más en el "largo plazo". La consecusión de sus principios programáticos, pasaba necesariamente por un proceso acumulativo, en el cual las luchas no estaban jugadas a un fenómeno revolucionario de inmediata resolución, sino al cumplimiento progresivo de los objetivos de sus programas mínimos. De todas maneras, las dificultades que encontraban los socialistas, sobre todo a principios de siglo, no dejarán de golpear sus filas, pero, no tanto, en las formas de deserciones individuales, seguidas de un proceso de renovación, con la incorporación de nuevas camadas de militantes, sino a través de deserciones colectivas de carácter políticoideológico. De ello testimonian, las escisiones de 1898 -aunque efímera-protagonizada por los Socialistas Colectivistas y la definitiva de 1906, encarnada por los futuros Sindicalistas Revolucionarios.

El otro factor determinante, que opera sobre las duraciones de la actividad política es el de las persecuciones.

Militantes que sufrieron persecución

\begin{tabular}{|c|c|c|c|c|c|}
\hline \multicolumn{2}{|c|}{ Persecución constatada } & \multicolumn{2}{|c|}{ Sin información } & \multicolumn{2}{|c|}{ Total } \\
\hline $\mathrm{N}^{\circ}$ & $\%$ & $\mathrm{~N}^{\circ}$ & $\%$ & $\mathrm{~N}^{\circ}$ & $\%$ \\
\hline 151 & 19 & 627 & 81 & 778 & 100 \\
\hline
\end{tabular}

Por la forma fragmentaria como nos llega la información sobre las persecuciones, podemos suponer que el porcentaje, puede ser, en realidad, más clevado. De todas maneras, un $19 \%$ de militantes que han sufrido algún tipo de 
persecución es de por sí significativo. Es evidente, que lo que hemos llamado genéricamente "persecución", engloba situaciones de diverso tipo.

Además, registramos variaciones en el tipo de persecuciones según los períodos. Y estas variaciones tienen relación con una cuestión más global, como es la representada por los cambios en las políticas del Estado hacia el movimiento obrero. Hasta 1902, la represión sobre los militantes obreros, es predominantemente selectiva y concentrada en los anarquistas y se reflejará principalmente en deportaciones y encarcelamientos de corta duración. Un poco más masiva solía ser, en ocasión de algunas huelgas que afectaban "gravemente al orden público" como en los casos de La Fraternidad y panaderos o en la virtual huelga general de Rosario de 1896. Allí, la represión alcanzaba a militantes menos conocidos y en fin, a muchos "oscuros" huelguistas. Pero, de todas maneras, estos no eran sino fenómenos episódicos.

Después de la huelga general de 1902 , se hace visible un cambio en la actitud del Estado hacia el movimiento obrero. Si por un lado, aparecen algunas tentativas "integracionistas", como lo ejemplifica particularmente el frustrado intento de sancionar un Código de Trabajo en 1904, por otro lado se lanzará una represión sistemática hacia el movimiento obrero, que comprenderá tanto a los movimientos masivos como la persecución individual de los militantes, especialmente a los anarquistas.

La sanción de la llamada "Ley de Residencia", por la cual el Poder Ejecutivo podía expulsar del país a los "extra njeros indeseables", se convertirá en un instrumento efectivo de represión contra el movimiento obrero. Entre fines de 1902 y comienzos de 1903 numerosos militantes serán deportados, a Uruguay, o a sus países de origen, especialmente a Italia y España. Las deportaciones, aunque no tan masivas, se seguirán aplicando durante el curso de la primera década del siglo, en forma frecuente, hasta que el mecanismo se perfecciona con la "Ley de Defensa Social" de 1910, por la cual no sólo, se podía sancionar a los extranjeros, sino también a los argentinos, deportándolos al penal de Ushuaia, en Tierra del Fuego. No obstante, la Ley de Residencia, será aplicada, en alguna oportunidad, no sólo a extranjeros sino también a nativos argentinos, como fue el caso de Francisco Arrillini, tal como lo denuncia $L a$ Protesta.

Otras formas frecuentes de persecución eran el encarcelamiento o el arresto, más temporario, y las violentas agresiones policiales, que a veces terminaban con heridas graves o la muerte. No hemos contabilizado otras formas frecuentes de persecución, no tanto basadas en la violencia física, sino en la discriminación, tal como las "listas negras" de las empresas y organizaciones sindicales patronales, que eran frecuentemente practicadas.

Las represiones y las deportaciones, en particular, influían notablemente, sobre el "estilo" y la duración de las militancias. Una cuota, no muy grande, pero significativa, de biografias nos revelan un tipo de militantes "trashumante" generalmente como consecuencia de la coerción- que por ejemplo, fugado de Ita lia por persecuciones, se afinca en Brasil, desde donde debe huir ante nuevas amenazas, para 
llegar a Argentina, desde donde será deportado a Montevideo o a su país de origen. En los casos que el destino de la deportación era Montevideo, los regresos a la Argentina, al poco tiempo, son abundantes. También, lo eran las fugas de deportados desde el barco que los trasladaba a Montevideo.

Los socialistas, no están exentos de persecuciones, pero éstas son menos frecuentes y menos intensas que la de los anarquistas. La persecución, la deportación - la fuga preventiva, eran bastante frecuentes entre algunos de los militantes a narquistas, y esto contribuye a darnos un perfil, bastante nítido, de los partidarios de esa corriente.

Los exiliados "voluntarios" o las deportaciones legales, nos llevan a la imagen de un tipo de militante "internacional", que en la tarea de constituir un Diccionario Biográfico del Movimiento Obrero Latinoamericano, debería figurar en varias "secciones nacionales" al mismo tiempo. Veamos, algunos casos por ejemplo: Oreste Ristori, fugado de Italia, milita en Brasil y Argentina. Rouco Buela o Virginia Bolten, expulsados de Argentina se convierten en figuras notorias del movimiento obrero uruguayo. Y también el proceso inverso: Luis Emilio Recabarren, una de las figuras notorias del movinuento obrero chileno, pasa algunos años de exilio en Buenos Aires, en donde descolla en el gremio de los tipógrafos y en las filas socialistas.

$\mathrm{Si}$ hasta ahora, hemos estado acostumbrados a leer explicaciones sobre la formación del movimiento obrero argentino en términos de "influencias extranjeras", lo que nos parece insuficiente, tal como veremos más adelante; se nos presenta, a hora, un fenómeno de otro tipo. Sería interesante verificar, lo que podríamos denominar el "efecto de retorno", es decir, cuál es la posible repercusión que en sus países de origen o en otros países de militancia de tránsito, tiene la vuelta o la llegada, de esos militantes portadores de una experiencia tan particular como fue la Argentina.

Otro de los temas, que merece un análisis especial, es el de la participación de la mujer en el movimiento obrero. Todo indica, que según los porcentajes, se trata eminentemente de un movimiento de varones. En efecto, el número de mujeres que hemos detectado, es varias veces inferior al de varones. Sin embargo no notamos una discriminación en cuanto a los dominios en los cuales las mujeres participaban. Así, encontramos a Virginia Bolten agitando en el acto del $1^{\circ}$ de mayo de 1890 en Rosario; o a Pepita Guerra escribiendo textos doctrinarios sobre el feminismo en La Voz de la mujer. O también, a Cecilia Baldovino realizando propaganda feminista desde las páginas de La Vanguardia.

La menor participación de las mujeres, en el nacimiento del movimiento obrero de la época, parece evidente. Y esto, quizás, tenga relación con la predominancia de oficios calificados y artesanales, en los cuales las mujeres eran minoritarias. Aunque, las mujeres, en evidente minoría, aparecen en todos los tipos de militancia, sobresalen en la prédica del feminismo, que aunque con diferencias, es en la época, un tema común a anarquistas y socialistas. 


\section{Aproximación a un perfil}

La primera cuestión que debemos abordar es la de determinar en qué medida el trabajo de cuantificación e interpretación que hemos hecho con datos biográficos de 778 militantes del movimiento obrero nos permite aproximarnos a un "perfil".

El primer problema que se nos plantea, es el de la "representatividad" de ese conjunto de nombres. Por un lado creemos que esas 778 biografias son suficientemente representativas como para señalar algunas tendencias principales. Pero, por otro lado, tal como dijimos al comienzo, el trabajo biográfico, tal como lo concebimos en este caso, queda siempre abierto y por lo tanto -en cierto sentidonuestras conclusiones serán "provisorias".

Que el conjunto de las biografias analizadas sean representativas, no quiere decir que estén "todos" los militantes "conocidos" de la época. De alguna manera, esos 778 casos tienen un carácter de "muestra". Algún erudito del movimiento obrero del período no dejará de señalarnos la ausencia de tal o cual nombre, y entre ellos, algunos, conocidos. No obstante, creemos que el número es lo suficientemente representativo como para que podamos sacar algunas conclusiones de importancia.

El segundo problema, es que muchas de estas biografias son incompletas. Pero esto ya lo sabíamos al iniciar nuestra empresa. Algunas quedarán incompletas para siempre. En otras, es posible, que una búsqueda más exhaustiva en archivos extranjeros o la continuidad del trabajo biográfico en épocas posteriores, pueda "mejorarlas". Pero, es evidente, que el carácter incompleto de ese conjunto de biografías está dado, fundamentalmente por la propia naturaleza del tipo de militancia que se practicaba en la época y sobre todo, por quienes eran, la mayoría de los que la practicaban.

De todas maneras, este fenómeno incide en que no en todos los rubros que hemos querido considerar, tengamos los mismos resultados en los porcentajes de informaciones obtenidos. Así, por ejemplo, la tendencia política, la actividad profesional, son mucho más fácilmente detectables que la nacionalidad o el hecho de si los extranjeros, tenían militancia previa o no, a su llegada al país. En consecuencia, en algunos aspectos, nuestras conclusiones serán más "firmes" y en otros no serán sino "tendencias" de posible rectificación.

La segunda cuestión que debemos abordar, es la de intentar responder a la pregunta sobre quiénes eran, socialmente hablando, esos militantes. La respuesta no admite demasiadas dudas: en su mayoría son obreros calificados y artesa nos. En la minoría, encontramos a un núcleo de intelectuales, casi todos escritores, periodistas o profesionales liberales; a un sector pequeño de trabajadores manuales no calificados y a un grupo al que hemos denominado "militantes de profesión".

Los sectores de la actividad económica de la cual provienen los obreros y artesanos es coincidente con la estructura ocupacional de la época, a excepcrón de los casos, que hemos señalado, de los militantes de La Fraternidad y el de los Tipógrafos. Por otra parte, la presencia importante de militantes de gremios relaciona- 
dos con la alimentación y el vestido -panaderos y zapateros, por ejemplo- están indicando el grado de conflictividad en esos sectores que afectaban al consumo y por consecuencia, en alguna medida, directamente a la élite dirigente y por lo tanto, sujetos desde temprano, a una "especial atención" por parte de los poderes públicos (6).

La notoria menor presencia de obreros no calificados, responde a dos cuestiones principales. Por un lado, la estructura sindical dominante en el período es la del "sindicato por oficio". Este tipo de organización deja afuera, generalmente, a los peones. En segundo lugar, la sindicalización masiva de los sectores no calificados de trabajadores, comienza recién a principios del siglo XX. El caso de la Federación de Obreros Ferroviarios, que hasta cierto punto rivalizará con La Fraternidad, es un buen ejemplo.

La presencia mayoritaria de trabajadores manuales sobre los intelectuales no nos dice todo, todavía, sobre el real peso que unos y otros tenía n en el movimiento obrero. Esta es una cuestión compleja, que requiere algunas constataciones previas. En primer lugar, clsector de intelectuales no es homogéneo en cuanto al tipo de actividad política. Algunos de ellos, son "simpatizantes" del movimiento obrero y reflejan estas simpatías en sus escritos. Otros tienen una actitud militante más directa, como en los casos de Juan B. Justo, José Ingenieros, Leopoldo Lugones, Manuel Ugarte, Alfredo Palacios u otros, entre los socialistas y a Pietro Gori, Alberto Ghiraldo o Pascual Guaglianone entre los a narquistas.

La presencia de obreros y artesanos en organismos de dirección de las instancias políticas del movimiento obrero, es indudable. No obstante, es evidente que los intelectuales tuvieron un peso mayor de el que se deduciría de los porcentajes de su presencia en el conjunto de los 778 nombres considerados. En el caso de los socialistas, la cuestión es bastante evidente. Desde 1894 con la creación de $L a$ Vanguardia y sobre todo desde 1896 con la orga nización definitiva del partido a través de la realización de su primer congreso, los militantes de origen intelectual, los médicos y abogados, transformados en militantes de profesión, desempeñan un papel de primer orden.Por su mayor descentralización, el caso anarquista dificulta, a primera vista, una apreciación simúlar. Sin embargo, la presencia de hombres como John Creaghe, médico de profesión o la del escritor Alberto Ghiraldo, en la redacción de La Protesta o el rol organizador que tuvo Pietro Gori, para no dar más ejemplos, indican también una presencia hegemonizante de los intelectuales en ese movimiento.

Incluso, la "invasión" de los intelectuales no deja de manifestarse en las organizaciones propiamente obreras, como eran los sindicatos y las federaciones sindicales. Sospechamos, por ejemplo, que el papel que le cupo al "tenedor de libros" y conocido militante anarquista internacional, Ettore Mattei, en la redacción de El Obrero Panadero, era mucho más influyente en las decisiones políticas, que las que podía n tener los abogados o ingenieros colaboradores "honorarios" de La Fraternidad.

Por otra parte, la lectura en los periódicos de la época de los congresos de las federaciones obreras, nos revela la reincidencia de episodios en los que se cuestiona 
a algún delegado por que no pertenecía al gremio al cual representaba. En efecto,la lista de congresales -tanto en el caso de la FOA, luego FORA, o de la UGT-nos muestra que ciertos militantes de profesiones intelectuales, solían representar a gremios del interior o incluso, a veces, también de la Capital Federal.

Si no es dificil constatar una presencia determinante de militantes de origen intelectual en las instancias dirigentes del movimiento obrero, la cuestión se hace todavía más compleja si consideramos que la militancia política implicaba una cierta "intelectualización" o si se prefiere "desproletarización" de muchos de esos militantes. Esto se manifiesta en el "destino" posterior de algunos de esos militantes que culminaron sus carreras como periodistas. Tempranamente, un caso interesante es el de Victory y Suárez, tipógrafo, y uno de los primeros en vincularse con la Prinera Internacional, que ejercerá luego el periodismo y hasta llegará a ser funcionario de la Sociedad Rural. En épocas postetiores, la "militancia profesional" favorecería, tambićn, esa tendencia. Muchos de esos militantes, que comenzaron en su juventud en una profesión manual terminaron, luego, en actividades intelectuales, después de haberlas ejercido, primero, por razones políticas.

Por otra parte, muchos de esos obreros calificados y artesanos de los años ochenta y noventa son intelectuales sui generis. Son, en general, autodidactas, con una cierta formación político-intelectual y lectores voraces de algunos textos que de este tipo, se publican en la época. El hecho, que José Ingenieros hubiera hecho su formación juvenil intelectual básica en la biblioteca de su padre, Salvatore Ingenieros, es una prueba de ello. Artesanos que controlaban su propio proceso productivo, que carecen de horarios fijos y relación de dependencia y que poseen un cierto grado importante de instrucción, actuarán, sobre todo hasta mediados de la década del noventa como los "intelectuales del movimiento obrero", hasta su desplazamiento -parcial-por los "verdaderos" intelectuales.

Volviendo ahora, a esos "verdaderos" intelectuales, debemos preguntarnos también sobre cuál fue su "destino" posterior. Algunos, permanecerán fieles basta su muerte, que a veces será trágica, a su filiación política. Otros desertarán, y a veces tempranamente. En ese sentido resulta premonitoria la aseveración de José Ingenieros en una polémica epistolar con el intelectual anarguista Pascual Guaglianone, desarrollada a principios de siglo. Me encuentro en el "camino de Damasco" dice Ingenieros aludiendo metafóricamente a la "conversión paulatina" y $t u$-refiriéndose a Guaglianone-también lo recorrerás en algún momento(7). En efecto, Guaglianone dejará, tiempo después, las filas anarquistas, para terminar siendo asesor del ministerio radical de Le Breton. Para algunos intelectuales, el "deslumbramiento" por el movimiento obrero fue efímero -aunque con duración variada - y si es necesario otro ejemplo, el de Leopoldo Lugones, puede ser muy ilustrativo.

En suma, el grado de "intelectualización" de los sectores dirigentes de ese primer movimiento obrero argentino es alto, si se tiene en cuenta, tanto la presencia significativa de "intelectuales profesionales" de origen de clase media, como si tenemos en cuenta a los autodidactas de origen obrero o artesano. Y esto lo prueba 
el porcentaje relativamente alto que hemos detectado de militantes que escribían con cierta regularidad en publicaciones periódicas y que suponemos puede ser aún mayor.

La tercera cuestión de envergadura que debemos afrontar es la de la nacionalidad de los militantes y su posible influencia en el perfil global. Esta cuestión es una de las más importantes. Durante mucho tiempo ha prevalecido en la historiografía argentina la versión que el predominio del anarquismo en el movimiento obrero estaría dado por la presencia mayoritaria de militantes de origen italiano y español que habrían importado ese tipo de ideología, que serían características de esos paises. Quizás, el primero en exponer este tipo de interpretación, fue el militante e historiador socialista Jacinto Oddone, pretendiendo justificar, de esa manera, las mayores dificultades de su tendencia política para consolidarse en el movimiento obrero(8).

Con este tipo de interpretaciones seguimos moviéndonos en el terreno de las influencias, concepto frente al cual, Robert Paris, opone la categoría gramsciana de traductibilidad. "Influencias", supone la introducción y reproducción de ciertas ideas. "Traductibilidad", supone un trabajo creador en la adaptación de ciertas ideas. "Influencias" supone admitir una simple expansión de las ideas a narquistas argentinas como producto de una importación a través de los migrantes. Es decir, que -siguiendo esa lógica- si el número de migrantes a lemanes hubiera sido mayor que el de italianos o españoles, el movimiento obrero argentino de fines de siglo XIX y principios del siglo $\mathrm{XX}$ hubiera sido socialdemócrata. Lo que revela, evidentemente, un notorio simplismo (9).

Una versión diferente, inspirada en esa categoría de "traductibilidad" es el artículo de Ricardo Falcón, de 1986, en el que se propone una interpretación de la expansión del a na rquismo en Argentina por su capacidad de dar respuestas frente a algunas cuestiones centrales -tales como el rol del Estado, la cuestión étnica y la cuestión social- y no solamente por la mayoritaria presencia de migrantes italianos y españoles (10).

En todo caso, la discusión sigue abierta, o mejor dicho, recientemente se ha abierto. El problema que se nos presenta a nosotros es el de saber hasta qué punto nuestras conclusiones pueden interferir en una polémica interpretativa como la que hemos expuesto. La primera constatación, es que el porcentaje de informaciones que disponemos es bastante reducida como para avanzar en conclusiones demasiado definitivas. En efecto, tal como dijimos, disponemos de datos sobre la nacionalidad de los militantes, sólo en el $22 \%$ de los casos, lo cual nos llama a la prudencia interpretativa. No obstante, estos porcentajes nos permiten deducir algunas tendencias más o menos evidentes.

En los primeros períodos, el porcentaje de extranjeros entre los militantes es casi absoluto y esto tiende a corroborar varias tesis al respecto. No sólo las más conocidas sobre la influencia global de los migrantes extranjeros en el mundo urbano argentino, sino también las que se refieren a un rol fundador de los extranjeros en el incipiente movimiento obrero. Sin embargo, es evidente, que en períodos posteriores las 
tendencias registran algunas modificaciones significativas.

La presencia de militantes argentinos comienza a adquirir cierta importancia en los años noventa. Primero, sobre todo, a partir de intelectuales de clase media y de algunos obreros hijos de extranjeros. Pero, a partir de 1900 , la tendencia parece invertirse, notándose una mayor presencia de obreros de nacionalidad argentina. Esta conclusión que se desprende del análisis de los casos biográficos, parece coincidir con la hipótesis de Iaacov Oved, quien afirma la existencia de una camada de militantes argentinos en la reconstrucción de la FOA desde 1903, luego de las represiones violentas sufridas desde el año anterior.(11)

Así, como tenemos la presunción que hasta fines de siglo el número de extranjeros es mayor del que hemos registrado, habida cuenta, de una cuota muy grande de casos en los que no se ha obtenido información sobre la nacionalidad, creemos que después de 1900, puede estar ocurriendo lo mismo con los argentinos.

La relación entre nacionalidad y tendencia política nos revela una diferencia a favor de los socialistas en lo que hace al porcentaje de argentinos, respecto a los a narquistas. En principio, la presencia de algunos casos de natu ralización de extranjeros y de un núcleo de intelectuales nacidos en el país, parece estar en la base de la diferencia. No obstante, en los primeros años del nuevo siglo se hace evidente un incremento de los a narquistas de origen argentino.

En cuanto a las nacionalidades extranjeras se combinan dos fenómenos. Por un lado, las proporciones respetan los índices generales de extranjeros por grupo de origen en el conjunto de la población. Y por otro, aparecen distorsiones, ya hemos citado el caso notorio de los alemanes, por las oleadas de migraciones por persecuciones políticas. La relación entre nacionalidad extranjera y tendencia política, marca algunas tendencias más o menos definidas: mayoría importante de anarquistas entre los españoles; también entre los italianos, pero en ese caso, con alguna presencia socialista; predominio anarquista entre los franceses y notoria mayoría socialista entre los alemanes. Finalmente, tenemos información sobre experiencias múlitantes en el país de origen en menos del $50 \%$ de los casos. En efecto, sólo hemos podido constatarla en el $41 \%$ de las situaciones. Este porcentaje no debe sorprendernos, dado el hecho, que por lo menos hasta los años noventa, muchos de los iniciadores del movimiento obrero argentino son emigrados políticos.

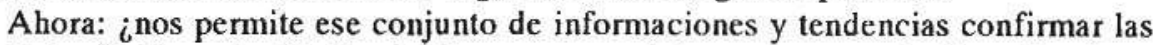
tesis de las "influencias"?. Nos inclinamos a concluir que no y que la discusión sigue abierta y sujeta a nuevas investigaciones y debates. En primer lugar, en este rubro los datos disponibles no parecen lo suficientemente representativos como para marcar una tendencia definitiva. En segundo lugar, si la mayoría anarquista y la escasa presencia socialista, entre las filas de españoles, tendería a avalar la hipótesis de las "influencias", podríamos hacer lo mismo con el caso francés y deducir una hegemonía anarquista en Francia.

Además, no sabemos cuantos son extranjeros dentro del $56 \%$ de los que no tenemos información, ni cual era su origen nacional, ni si tenían o no militancia 
previa. Más aún, estamos refiriéndonos a casos de militantes que, aun cuando "oscuros", en la mayoría de las situaciones, hemos podido recoger sus nombres porque tuvieron alguna participación más o menos destacada. Pero, sin duda el movimiento obrero argentino incluía también un número, varias veces mayor, de hombres todavía "más oscuros" sobre los cuales no tenemos información ninguna.

$\mathrm{Y}$ es aquí, donde un trabajo de este tipo revela sus limitaciones. Hemos podido constatar un peso importante de los extranjeros en los comienzos del movimiento obrero; hemos logrado vislumbrar ciertas tendencias en la relación entre algunas nacionalidades extranjeras y filiaciones políticas; hemos alcanzado a determinar porcentajes provisorios sobre militantes, que tenían una experiencia anterior; pero seguimos ignorando mucho respecto, de una buena parte de nuestros 778 nombres y "todo" del resto de los trabajadores que de una u otra manera, participaban en el movimiento obrero. Sabemos, que una minoría militante llegaba al país portadora de ciertas ideas, pero no sabemos cuántos de los seguidores de esa minoría adherían a ella en el país y por qué lo hacían.

Otra interpretación, que aparece como cuestionada es la que ubica una distribución entre tendencia política y actividad profesional, según la cual el predominio del anarquismo entre 1895 y la primera década del siglo estaría dado por la existencia de un número importante de profesiones de base artesanal. Esta interpretación ha sidoalentada, en particular, por los historiadores comunistas y un buen exponente de ella es el historiador soviético V. Ermolaiev(12). La interpretación, descansaba en la idea que el a narquismo, que preconizaba la distribución de los bienes de consumo debía necesariamente corresponderse con esos sectores artesanales, mientras que el "marxismo" que bregaba por la socialización de los medios de producción, tendría su apoyo preferencial en los "obreros".

Hemos renunciado a tabular las informaciones que disponemos sobre distribución de oficios en relación con tendencias políticas, porque ellas no nos revelan nada en particular. Tanto anarquistas como socialistas tienen un fuerte anclaje entre los obreros calificados y artesanos y ambos lo tienen también en sectores no artesanales como el caso de portuarios y transporte. Además, los a narquistas eran, particularmente, fuertes en una de las pocas fábricas importantes existentes en el país en la década del noventa; la Refinería de azúcar de Rosario. Además, es interesante recordar el caso de La Fraternidad, cuyos militantes no parecían inclinados ni a "distribuir los bienes de consumo" ni a "socializar los medios de producción" sino a reforzar la profesión y sus condiciones materiales de vida, mediante la acción sindical, la vinculación con el Estado y con las compañías ferroviarias.

Aunque con variantes, según los sub-períodos, se mantiene, sin embargo, a lo largo de la etapa que estudiamos, un "estilo" predominante de actividad política y sindical. El $64 \%$ de los militantes registraba actividad sindical. Además, podemos agregar que una buena parte de los que no tenemos detectados como "sindicalistas", realizaban actividades de propaganda que en muchos casos tenían que ver con lo sindical. Esto es, particularmente, fuerte en el anarquismo, por lo menos en sus 
sectores "organizadores". Finalmente, el ana rquismo argentino de principios de siglo tuvo una fuerte connotación de "anarco-sindicalismo".

En cambio, la actividad propagandística prevalece entre los anarquistas "antiorganizadores", que rechazaban la actividad sindical. En los socialistas, la cuestión aparece más matizada. Una porción importante de éstos era de tipo sindical, pero, aparecen también los propagandistas y los "organizadores", responsables de círculos o comités.

Un número importante de militantes, probablemente mayor del que hemos detectado, escribe en los periódicos. Aquí cabe hacer una distinción, entre directores o redactores permanentes, y colaboradores ocasionales. El tipo de participación escrita que parece predominar es la "intermedia", es decir, los que escriben con regularidad, pero episódicamente.

El movimiento obrero de la época pasó por etapas de semi-legalidad y por etapas de declarada ilegalidad, aunque las consecuencias no fueron las mismas para los anarquistas, que para Ios socialistas o los militantes de La Fraternidad. La frecuencia de las persecuciones y la semi-clandestinidad que rodeaba a la actividad militante, refuerza la idea del militante como un "hombre no común".

\section{Conclusiones finales}

La primera de nuestras conclusiones es que, finalmente, hemos podido delinear un cierto perfil, aunque este perfil, como lo sabíamos desde un comienzo, es incompleto.

En segundo lugar, sabemos que la mayoría de los militantes del movimiento obrero son trabajadores manuales, obreros calificados y artesanos, en alta proporción, con la presencia de un sector de intelectuales de profesión, que desempeña funciones políticas importantes.

En tercer lugar, hemos detectado algunas tendencias en cuanto a la nacionalidad. En los primeros tiempos parecen predominar los extranjeros, y a principios del nuevo siglo esta primacía disminuye ante una mayor presencia de argentinos. Sabemos, también, que en las épocas pioneras la mayoría de los militantes, emigrados políticos la mayor parte, había tenido una experiencia política anterior. Sin embargo, no podemos determinar la envergadura de este fenómeno en el conjunto del período que hemos abarcado.

En cuarto lugar, hemos constatado que se trata de un movimiento en el que predominan los varones sobre las mujeres. Sin embargo, éstas, aunque registren un número inferior, alcanzan, en ciertas circunstancias, posiciones destacadas, no tanto en el plano sindical sino en el de la propaganda y agitación.

En quinto lugar, se confirma un hecho ya suficientemente conocido, el peso mayoritario de anarquistas y socia listas en el movimiento obrero. Si bien la distribución de fuerzas parece haber sido pareja durante los años noventa del siglo XIX, en la década 
siguiente se vislumbra una mayor presencia anarquista, sobre todo en el plano sindical. Fuera de esas tendencias, aparece un número importante de militantes de La Fraternidad, que representaba una concepción diferente de la actividad sindical. Se revelan algunas "preferencias" por nacionalidades extranjeras entre socialistas y anarquistas, pero no en todos los casos el porcentaje de informaciones obtenidas permite conclusiones definitivas.

En sexto lugar, si la mayoría de militantes registra actividad sindical, como era de esperar, por lo menos para después de 1895 , es significativo el porcentaje de los que aparecen dedicados solamente a funciones propagandísticas u otras. Es significativo también el número de militantes que realizan actividades propagandísticas en forma escrita.

En séptimo lugar, entre esos militantes dedicados a actividades no sindicales y particularmente en el caso del anarquismo, a parece un sector de "profesionales" de la actividad política.

En octavo lugar, si bien un sector de militantes registra una actividad duradera en el tiempo, las constantes persecuciones y la frustración de ciertas expectativas de "corto plazo", sobre todo entre los anarquistas, hacen que las duraciones de los períodos de militancia sean variados y a veces directamente cortos.

\section{NOTAS}

(1) PARIS, Robert.

(2) Ibídem

(3) Nos referimos en particular a la reconstrueción de la historia de la Primera Internacional en Argentina, en la cual algunas biografias facilitaron enormemente esa tarea, véase FALCON, Ricardo. Los origenes del movimiento obrero. 1857-1899, CEAL., Buenos Aires, 1984.

(4) AGNELLI, F y CHTTTI, B. Cincuentenario de "La Fraternidad", Bs.As., 1937.

(5) ABAD DE SANTLLLAN, Diego. El movimiento anarquista en Argentina. Argonauta, Buenos Aires, 1930.

(6) Seguimos aquí la idea expuesta por Jean de Gaudemar en La movilización general, La Piqueta, Madrid, 1982 .

(7) Según biografía de José Ingenieros realizada por Ricardo Falcón, de acuerdo a fuentes expuestas en el A péndice Bibliográfico.

(8) ODDONE, Jacinto. Historia del socialismo argentino, CEAL, Buenos Aires, 1983. T. I y II.

(9) Thidem.

(10) FALCON, Ricardo. "Izquierdas, Régimen políico, Cuestión étnica y Cuestión social en Argentina (1890-1912)". en ANUARIO N` 12 Escuela deHistoria, Facultad de Humanidades y Artes, U.N.R., Rosario, 1986-1987.

(11) OVED, laacov El anarquismo y el movimiento obrero en Argentina, Siglo XXI, México, 1978.

(12) ERMOLAIEV, V. "Naissance du mouvement ouvrier" en Recherches Internationales à la lumière du marxisme, num 32, Paris, Juillet-aoùt, 1962. 


\section{APENDICE I}

Indice de Nombres

A

ABAD, Gabriel.

ABADIA.

ACHA, J.M.

ADAMS, Francisco.

AGUIRRE, Clodomiro. AGGIO, Carlos.

AIMANI.

AKSELRUD, Usher.

ALBANI, Eugenio.

ALBIZU, A.

ALCON, José.

ALDANI, Juan.

ALDAO, J.

ALDIGHIERI, Tiziano.

ALESINI, Luiggi.

ALFONSIN, Ricardo.

ALIVERTO, Juan.

ALMADA, Esteban.

ALMEIRA, Ramón.

ALMIRON, Cándido.

ALONSO, Federico.

ALTGELT, Carlos A.

ALTUVE, José.

ALVAREZ, Agustín.

ALVAREZ, Antonio.

ALVAREZ, Serafín.

AIZUE, Francisco (o ALZUET).

AMBRINI, José.

AMIR, Vicente.

ANSELMI, J.

ANSELMO, J.

APELLIANIS, Francisco.

APSELL, P.

AQUILES, Lorenzo.

ARAN, J.

ARANA, Emilio Z.

ARACEMI, Máximo.

AREVALO, Antonio.

AREVALO, Aurelio.

ARIASCHAVARRIA, Rafael.

ARIENTI, Carlos.

ARIENTI, Eneas.

ARIENTI, Teresa $\mathrm{Ch}$. de.

ARMAS, Domingo de.

ARRAGA, J.A.
ARREDONDO, $\mathrm{M}$.

ARRIETA, Agustín.

ARRILLINI, Francisco (o ARBILLINI).

AUBERT, A.

B

BACAICUA, Lorenzo.

BAJANDA, Víctor.

BAJES, Leoncio (o BAGES).

BAKU (ps.).

BALARINO, Santiago.

BALBI, Santiago.

BALDOVINO, Cecilia.

BALIÑo, José.

BALSAN, Carlos.

BALTA, V.

BALZARETTI, A.

BANETT, Anselmo.

BARBA, Jaime.

BARBAROSA, Ricardo.

BARBAZAN, José.

BARCELo, Antonio.

BARSANTI, Pedro.

BASALO, José.

BASSI, Víctor.

BASTERRA, Félix.

BATTAGLIA, José.

BATTY, T.

BATUZTINI, F.

BAUX, Jean.

BEAUCHAMP, Guillermo.

BEJAR, Víctor.

BELGIORNO, José.

BELOCCHIO, J.

BELTRAN, Orsini (o BERTINI).

BELLA, Andrés.

BELLETTI, Vico.

BELLUCI, A.

BENEDETTI, S.

BENITEZ, Domingo.

BENITEZ, I.

BENITO, Buenaventura.

BENNATI, $P$. 


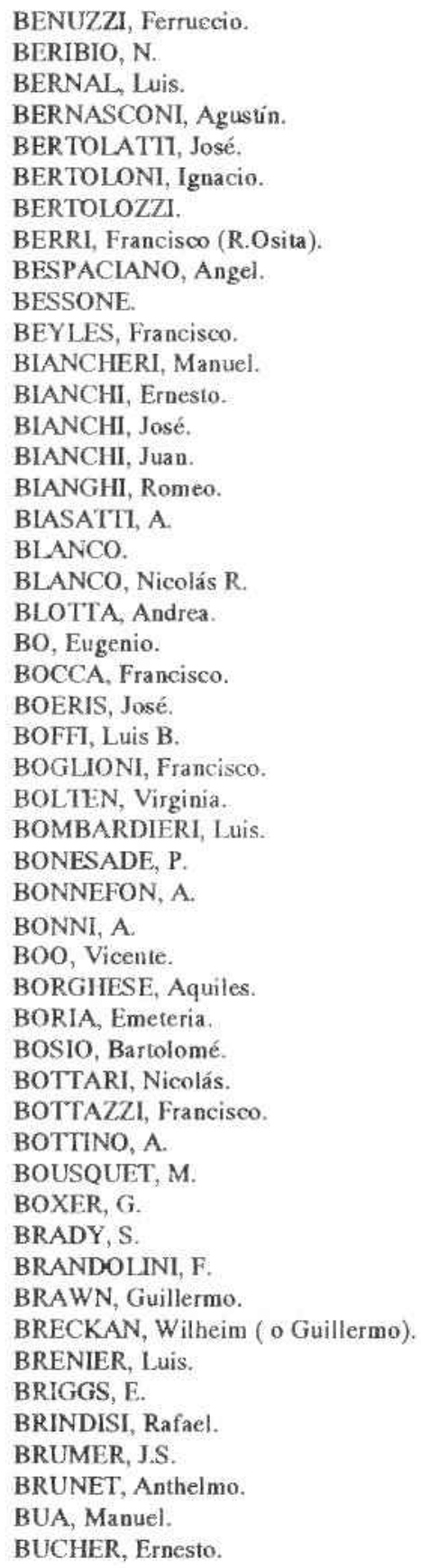

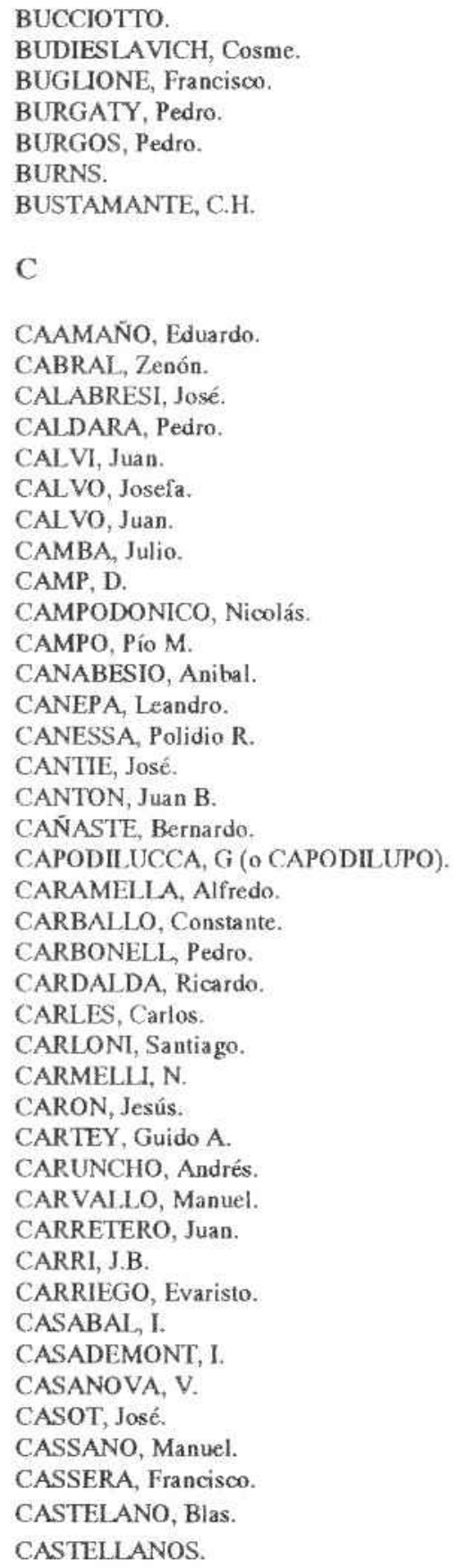


CASTRO, A.V.

CASTRO, Celindo.

CASTRO, Emilio.

CASTRO, J.A.

CASTRO, M.A.

CAUCERIO, L.

CAVALLERI, José.

CAVALLI, Pericles.

CAVEGGIA, Emilio.

CAVIDIA, M.A.

CAVOLLIA, Victorio.

CERDA.

CERLATTI, Francisco.

CIGLIUTTI, Francisco.

CILIBERTI, J.

CIMINAGHI, Giovanni.

CLARO, F.

CLARO, J.

COBOS, Manuel.

COLANDI, Luis.

COLOMBO, Víctor.

CONDE, J.

CONI, Gabriela de.

CONSORTI, Ferdinando.

CORAMINAS, Félix.

CORAZZI, Alfredo.

CORNEY, Germinal F.

CORTES, Mariano (ALTAIR).

COSCIA.

COSTA, Emesto.

COVILLA, D.

COZZI, Rodolfo.

CREAGHE, Juan.

CRUCES, Federico.

CRUZ, Pedro de la.

CUADRADO, Indalecio.

CUNEO, Francisco.

CUOMO, Juan.

CURET, Hipólito.

CH

CHACON, Antonio.

CHANDLER, George E.

CHARON, Augusto.

CHICHI, José.

CHIESA, Julio.

CHIODINI, $\mathrm{H}$.
D

DAGNINO, Esteban.

DAGNINO, Francisco.

DALY, J.J.

DALLISON, Ricardo.

DAMIANI, J.

DAROQUE, Vicente (o DAROQUI).

DEANDREY, Bartolo.

DE CICCO, José.

DECHESNER, Alfredo.

DELAFRANCLA.

DELARUE, Achilles.

DELFINO, Juan.

DEL VALIE IBARLUCEA, Francisco.

DELlacosta, Pablo.

DELLA LATTA, Gerónimo.

DENANBRIDE, Francisco.

DENIS, Miguel.

DENTONE, José.

DE TOMASO, Antonio.

DEUBERGE, $A$.

DIAZ, Zenón.

DICKMANN, Adolfo.

DICKMANN, Enrique.

DICKMANN, Máximo.

DIETRICH, Emile.

DIUNIDOU, Juan.

DI TULIO, Timoteo.

DOLSEI FONTANEL, Luis.

DONOFRIO, José.

DORMIDO, Antonio.

DOZO, Federico.

DUFRESNE, Emilio.

DUMARTE, Alejandro.

DUPONT, F.

DUPRET, E.

DURAND, A.

DURO, José.

DURO, Ramón.

E

EBELOT.

ECHAGUE, Alfredo.

ECHAGUE, Carlos.

ELORDI, Juan.

ESTRADA, Salvador.

EVANS. 
F

FAGAN, P.

FAGNANEA, Manuel.

FAGELLA, F

FANFANI, Juan.

FAURF, Silvestre.

FEA, $J$.

FERNANDEZ, Artonio.

FERNANDEL, José.

FIRNANDEZ, Manuel.

FERNANDEZ, $R$.

IERNANDEZ, Victor.

FERRER, A.

FERRER, Mariano.

FERRIOL Domingo.

FILTIER.

FIGUER A, José.

FINJ SCIII, Valprino.

FIORITTO, F.

FIRPO, Barolomé

FLAFSII, E

FI FTCIIER.

FO, Francisco.

FONDL VIL A, Miguel.

FOYE, Enrique.

IRACiA, José.

FRALDE, Giovanni.

FUEYO, Bautista

G

GAlA, Juan.

GALDEANO Gregorio.

GALETTI. Constante.

(iALIARDO, Antonio.

GALLARINI, Carlos.

GAIIERO, E.

(iALII,S.

GAIIO, I.

GAHO,P.

GANDOIFO, Agustin

GARASSINO, 1.

GARAY, Samuel.

GARBACCIO.

GARCIA BAISAS.

GARCIA, Benjamín.

GARCLA, C.

GARCLA, Eduardo (Gilimén).

G,ARCIA, Francisco.
GARCIA, José.

GARCIA Mariano.

GARCIA, Ramón.

GARFAGNINI, Dante.

GAR.IBALDI, Desiderio.

GAUTIIIER, $M$.

GEARLING, C.A.

GENTILI

GEORGF, Luis (o JORGE).

GERMAN, Próspero.

GERAN, Luis.

GEROSSA, J.B.

GER VASIN1, Luiggi.

GIIESSI, 5 .

GHIRAI DO, Alberto.

GLACOBINI, $S$.

GIGI IO, Iuiggi.

Gill, Antouio.

GII ARDI, D.

GII BERT.

GIII. Amadeo

GIMENEL, Angel M.

GIMENEL, Psteban.

GIMENEZ, José.

GINO Mario.

GODOY, Fulgencio.

GOMEZ, Alejandro.

GONZALEZ GARCIA, Eduardo.

GORI. Pedro.

GOYENECHE, Edelmiro.

GRANDE, E

GRANDI, G.

GRANDIN, José.

GRANCINI, J.

GRANELLI, Luis

GRANT, P.

GRATACOS

GRELIAND, Battista.

GREENWOOD, G.

GRIS. Copérnico.

GUAGLLANONE, Pascual.

GUtrRRa, Manuel.

GUERRA, Pepila.

GUERRERO, Mateo.

GUEVARA, D.

GUIIERRE $Z$, F.A (FAG LIBERT). 
H

HANGEREL, Jacobo.

HARBEN, Abelardo.

HAR VEY, Isaac.

HAUFMAN, H.W.

HESTER, J.

HOLWAY, Tomás.

HOMER, Enrique.

HUCHA, Joaquín.

HUGHET, Eugenio.

HUMMEL Gotoldo (o Gotardo).

HUSTER, Juan.

HUTEHINSON, G.

I

IASUA, Isidro.

IBARRA, Isidro.

IBARREN, $M$.

INGENIEROS, Salvatore.

INGENIEROS, José.

INGENIEROS, Pablo.

INGLAN LAFARGA, Gregorio.

IPARRAGUIRRE, José.

IRIANNI, Orazio.

ISLEÑO, J.

IZARRIAGA, Saturnino.

J

JACKEL, Marcelo.

JANIN, Francisco.

JAQUET, Franscisco.

JARA, Jacinto.

JEINKE, Guillermo.

JOB, Joseph Desiree Maxime (Le Mulatre).

JOB, Santiago.

JUSTO, Juan B.

K

KLEIN, Karl.

KRAUSSE, Otto.

KUEN, Víctor.

KUIIN, Augusto.

KUIRCHERCK, Julio.
L

LABOURDETTE, Juan.

LAFUENTE, Filomena.

LAGOS, Manuel.

LAGOMARSINO, M.

LAGOURDETTE, Ana.

LAINEZ.

LAITHON, L.

LAMBINET, E.

LAFRANCONI, S.

LARA, A.

LAREVA, Carmen.

LARROSSI, Domingo.

LATZKE, Augusto.

LAUREIRO, $M$.

LAUS, A.

LAYDA, Felipe.

LEBRON, J.

LEINICH.

LEXLAUSE, Julián.

LIGERI, $B$.

LINARES, José.

LISSO, Manuel.

LOCASCIO, Santiago.

LOMBET, Alejandro.

LOPERENA, Juan.

LOPEZ.

LOPEZ, José.

LOPEZ de la OSA, Pedro.

LOPEZ MONTENEGRO, José.

LOREDA, M.

LOREDO, Antonio.

LOVADINA, Mateo.

LOZZA, Alfonso.

LLORCA, Juan.

LUCHINI, César.

LUGONES, Leopoido.

LUGONI, Juan.

LUNA, Joaquín.

LUPANO, Alejandro.

LUPANO, Teodoro.

M

MAGDALENA, Antonio.

MAGRASSI, Luigi.

MAJOCCHI, Ettore.

MALATESTA, Errico. 
MALFASI, Angelo,

MALINATII.

MALORNY, Teodoro.

MALIOL, R.

MANRIQUE, Manuel.

MANTECON, Antonio.

MANTECON, Alejandro.

MARANTE, Manuel.

MARANEEZ, Angel.

MARCHISIO, Teresa.

MARGALL, José.

MARINO, Umberto.

MARNI, Juan.

MAROTTA, Sebastián.

MARSIGLIA, Antonio.

MARTI, Gombam.

MARTI, J.E.

MART1, Seferino.

MARTIAL, Edmundo.

MARTTN, José

MARTINEZ, Domingo.

MARTTNEZ, Eusebio.

MARTTNEZ, Josefa.

MARTINEZ, Manuel.

MAS y PI, Juan.

MASSA, Salvador.

MATHEUS, B.

MATHON, Carlos.

MATURANA, Manuel.

MATURI, Ignacio.

MATTERI, Héctor.

MAUL, Carios.

MAYA, A.

MAYORKA, J.

MAZZALUPI, V.

MAZZOLA, Geanbatista.

MELVIO, Martín.

MELLA, José.

MELLEIROS, José.

MENA, Agustín.

MENDEZ, José M.

MENGEN, Oscar (o MONGEN).

MENOTT1, Plinio.

MERCANTI, Domingo.

MERLINO, I.

MEYER GONZALEZ, Manuel.

MEZQUIRIZ.

MINANDO, J.

MINGAY, S.

MINGUZZI, Luisa de PEZZI (Luisa FORNI).
MOLINA, Juan.

MOLINA Y VEDIA, G, o J.

MOLINARI, Antonio.

MOLINARI, José.

MOMO, Francesco.

MONTAGNOLI, Santos.

MONTALE, Cristóbal.

MONTERO, Gerónimo.

MONIESANO, Arturo.

MONTESINO, Lucas.

MONZON, Agustín.

MORALES, Francesco.

MOREAU, Armand.

MORENO, J.

MORENOS.

MORESSINI, $J$.

MORIXE, Ignacio.

MOROS, Vicente.

MORRAT, $\mathrm{H}$.

MOSCA, Etrore.

MOSCA, Juan.

MOYA, Manuel.

MUCKE, Carlos.

MULLER, Germán.

MUÑOZ, Manuel.

MUÑOZ, María.

MUZio, Agustín.

N

NADALE, Homero.

NARIO, P.

NATA, Francisco.

NAVARRO, Antonio.

NEGRI, Ernesto.

NELSON, $M$.

NEUGEBAUER, Antón.

NIERI, Domingo.

NOBILE, A.

NOHKE, Gustavo.

O

OCAMPO, Juan.

ODDONE, Jacinto.

ODRISIO, Casme.

ORLANDI, Julio.

OROMI, Ignacio.

O VIDI, Rómolo. 
$\mathbf{P}$

PAGANELLI, Aurelio.

PAGANI, José.

PAGANINI, Antonio.

PAGANINI, Juan.

PALACIOS, Alfredo.

PALAU, Ramón.

PALMUCCI, Plinio.

PALLAS, Paulino.

PAMPANO, Juan.

PAÑEDA, José.

PAPINI, Napoleone.

PARODI, Juan.

PARDO, Bernardo.

PARIS, Domingo.

PASCUAL, Juan.

PASQUALINI, Alfredo.

PASQUOLINI, Dionisio.

PASSERINI, César.

PATRONI, Adrián.

PAYRO, Roberto.

PEDRON, Miguel.

PEDRONI, B.

PEGO, Manuel.

PEIRE, Alexis.

PELLICER PARAIRE, Antonio (Pellico).

PENCHE, Eduardo.

PENELON, José F.

PERAL, Manuel.

PEREZ, José.

PEREZ, Venancio.

PEREZ, Vicente.

PEREYRA, Jesús.

PERRY, Adrián.

PETERS, A.

PEZZI, Francisco (o C.FORNI).

PICHER, José.

PIETTE, Emile.

PINTO, Gregorio.

PIN̄ERO, Antonio (o Antonino).

PIOTT, Ernesto.

PIZZA, Miguel.

PLACIDO, Agustín.

PLANAS, Salvador.

POGGI, Luis.

POMMIES.

PONTE, Rafael.

PONTI, Alejandro.

PONTI, Pedro.
POURRILE, Estanilas.

POZZI, José.

PRIETO, Benito.

PROFESIONADO, José.

PUSSINI, Miguel.

Q

QUADRI, Luis.

QUINTANA, Francisco.

QUIROGA, Evaristo.

QUIROLE, Piere (Joaquín Alejandro FALCONET).

R

RABAZZA, Zacarías.

RAFFAINI, Luis.

RAFFAINI, B.

RAÑo, M. Lorenzo.

RAOUX, Jean.

RASMUNSEN, Luis.

RATT1, José.

RATTI, Pedro.

RAVEL, Elam.

RAVIOLI, José.

RAZAINI, $R$.

REAL, Bartolomé.

RECABARREN, Luis Emilio.

REGUERA, José.

REGUERA, Manuel.

REPETTO, Julio.

REPETTO, Nicolás.

RESTELLI, César.

REY, Felipe.

REY, M.

REYLES, Francisco.

RIELA, Bautista.

RIELLO, Francisco.

RIGANT1, Fortunato.

RIOS, Miguel.

RIPOLL, Baldomero.

RISTORI, Oreste.

RISSO, Domingo.

RISSO, Santiago.

RIVA, Arturo.

RIZZO, José.

ROBERT, J.

ROCA, José. 
ROCA, Rafael.

RODRIGUEZ, Emilio.

RODRIGUEZ, José.

RODRIGUEZ, Juan.

RODRIGUEZ, Leopoldo.

RODRIGUEZ, Victorio.

RODRIGUEZ PALANCA, Felipe.

ROGERS, A.

ROMERO, Nicanor.

ROMO, José.

ROSACRUZ, Vicente.

ROSALES, Hermenegildo.

ROSANOVA, F.

ROSAS, Juan.

ROSCOL, Roberto.

ROSELLI, Luis.

ROSENDO, Serafín.

ROSSIL, Felipe B. (Paraguayito).

ROUGE, J.

RUIZ, Juan.

RUIZ, Enrique.

RUIZ, Manuel.

RUIZ, Victoriano.

RUSSI, Pedro.

S

SADIER, Alex.

SACHSE, G.

SALAS, Nicanor.

SALES, Juan.

SALES, Juan $H$.

SALBANS, Baldomero.

SAN CLEMENTE, Jorge.

SAN JOSE, Victoriano.

SANCHEZ, Bernardo.

SANCHEZ, Florencio.

SANGUINETTI, Juan.

SANTIAGO, Joaquín.

SANTOLARIA, Emilio.

SANTOLIQUIDO, F.

SANZ, Vicente.

SAPORITI, Luis.

SARMIENTO, Nicanor.

SARRARU, Pedro.

SAURELLI, $P$.

SAVINO, Tommaso.

SCHAFER, G. (o SCHAEFER).

SCHAEFER, Juan.

SCHIAFINO, Guillermo.
SCHULZE, Guillermo.

SCHUMERT, Guillermo.

SEGARRAM, Antonio.

SERANTONI, Fortunato.

SERRA, Ricardo.

SERRANO, José.

SERRANO, F.

SESMA, Angel.

SEYFFERT, Osvaldo.

SICCARI, Francisco.

SIGARI, Francisco.

SILBERSTEIM, Abraham (o SILGERSCHTEIM).

SIMINAGII, Irma.

SIMONET, Eugenio.

SINOVILA, Ambrosio.

SOLDAT1, José.

SOLITRO, L.

SPINELLI, Venancio.

STARKE, Carlos.

STARTI, Federico.

STRATA, Egisto.

STRINGHINI, Nazareno.

SUAREZ, José.

SUAREZ, Sabino.

SUCRE, José.

$\mathbf{T}$

TACANI, Ludovico.

TAGLIARINI, Pedro.

TANGREDI, E.

TANNER, Alfredo.

TARELI,I, Pedro.

TEJADA, Francisco.

TELLO, Guillermo.

TERRIEBLE, Carlos.

THOMPSON, Alberto.

THOMPSON, Andrés.

THUSEND, Von der.

TORCCELLI, Alfredo.

TORELLI, Mauricio.

TORI, Amadeo.

TORNI, Enrique.

TORTI, Carlo.

TORTORELL, Lucas.

TORRENS ROS, J.

TORRES, J.B.

TOSSINI, Juan.

TOULOUSSE, Juan.

TRINGULIS, Nuncio. 
TROTTIN̄o, Adrián.

TROTINO, Angelo O.D.

TRUCCI, Juan.

TRUCCO, Francisco.

TRULEZI, Aquilino.

TUN̄ON, Adolfo.

TURTI, Oreste.

\section{$\mathbf{U}$}

UGARTE, Manuel.

UHILE, Adolf.

ULIANA, Antonio.

URRUTIA, León.

URRUZ, Víctor.

V

VAGO, Enrique.

VAGO, Eugenio.

VAIRE, Egidio.

VALENTI. Nicastro (o VICENTI).

VALENZUELA, A.

VALDASTRE, Alberto.

VALMACK, Eduardo.

VALLE, Diego J.

VALLOTTI, José.

VARELA, Antonio.

VAZQUEZ, F.

VAZQUEZ, Manuel.

VELA. Agustín.

VERMENGO, Rómulo.

VEZZANI, Felice (o "LUX FELIX').

VICTORY y SUAREZ, Bartolomé.

VIDAL, Basilio.

VIDAL, J.

VIDAL, Ramón.

VIGLIANO, Felice.

VILA, Juan.

VILLA. Mario.

VILLA, Napoleón.

VILLALBA, M.

VILLALON, Honorato.

VILLANUEVA, Domingo.

VILLAREAL, $C$.

\section{W}

WANZA, José.

WEBER, Teodoro.

WEITING, Wilheim.

WHILE, G.

WHISTON, A

WILMART de CLIMEST, Raymond.

WILSON, J. (o G.).

WINIGER, José.

z

ZAVALA, D.

ZACCAGNINI, Antonio.

ZAMORANO, C.

ZANTER, S.

ZAPOLETTI.

ZAPPALORTI, Ferruccio.

ZEO, Spartaco.

ZIEBIGKER, A.

ZINO, Leonardo.

ZUCCARINI, Emilio. 


\section{APENDICE II \\ Lista Bibliográfica y de Fuentes.}

\section{Archivos}

Archivo General de la Nación, Bs. As.

Archivo Nacional de París

Archivio Centrale dello Stalo - Roma

International Institute vor Sociale Geschedenis -Amsterdam, Colection Jung

\section{Obras}

ABAD DE SANTILLAN, Diego, Gran Enciclopedia argentina. Bs.As. Ediar,1956.

La FORA. Ideología y trayectoria. Bs.As. Proyección, 1971

El movimiento anarquista en Argentina.Bs.As.Argonauta, 1930.

AGNELIL, F. y CHITI, B. Cincuentenario de "La Fraternidad". Bs.As,, 1937.

BAYER, Osvaldo, Los vengadores de la patagonia irágica. Bs.As., Galerna, Tomo II y IV, 1973.

BELLONI, Alberto. Del anarquismo al peronismo: Historia del movimiento obrero argentino. Bs. As., Peńa Lilo, 1960.

BILSKY, Edgardo. La FORA y el movimiento obrero (1900-1910). Bs.As., CEAL,1984. -La Semana Trágica. Bs.As., CEAL, 1984.

BITLLOCH, R.E. Anarquistas y socialistas en Argentina 1880-1890. París CEHSAL, 1984.

CASARETO, Martín. Historia del movimiento obrero argentino. Bs. As., Claridad n.d.

COCA, Joaquín. El contubernio. Memorias de un diputado obrero. Bs.As., La Campana, 1980.

CUNEO, Dardo. El romanticismo político. Bs.As., Transición, 1955.

-El primer periodismo obreroy socialista en la Argentina. Bs. As., La Vanguardia, 1945.

DEL CAMPO, Hugo. Los anarquista. Bs.As., CEAL, 1971.

DIKMANN, Adolfo. Los congresos socialistas: 40 años de la acción democrática. Bs.As., La Vanguardia, 1936.

DIKMANN, Enrique. Recuerdos de un militantes socialista. Bs.As., La Vanguardia 1949.

Dictionnaire Biographique du mouvement ouvrier Français. Jean Maitron, Director,París, 1970.

Esbozo de Historia del partido Comunisia. Bs. As., Anteo, 1947.

FALCON, Ricardo. Los origenes del movimiento obrero. 1857-1899 Bs. As., CEAL 1984

CEHSAL, 1981.

-Bibliografia para el estudio del Movimiento Obrero Argentino en el siglo XIX. París,

GILIMON, E.G. . Hechos y comentarios. Bs. As.,Montevideo, México, 1932.

GIMENEZ, Angel. Los precursores del socialismo en la República Argentina. Bs. As., 1932.

guardia, 1927.

Páginas de la historia del movimiento socialista en la República Argentina., La Van-

Gli Italiani fuori d'Italia. Milán, Franco Angeli, 1983.

GODIO, Julio. Historia del movimiento obrero Argentino. Bs.As., Tiempo Contemporáneo, 1973.

GOLBERT, H. Rail-road Unionization in Argentina 1912-1929. YAL.E University, 1979.

IÑIGO CARRERA, Nicolás. Materiales para el estudio de la historia del movimiento obrero argentino: publicaciones periódicas oficiales, políticas y sindicales. Bs.As., S/F. Cuadernos del CICSO (mimeo).

IPARRAGUJRRE, Hilda y PIANETTO, Ofelia. La organización de la clase obrera en Córdoba 1870-1895.

Córdoba, Univ.Nac.Córdoba, 1968.

La Protesta en Certamen Internacional de La Protesta, Bs.As., 1927

LOPEZ, Alfredo. Historia del movimiento social y la clase obrera argeutina. Bs.As., Programa, 1971.

MARIANETTI, Benito. Las luchas sociales en Mendoza. Mendoza, ed. Cuyo, 1970.

MAROTTA, Sebastián. El movimiento sindical argentino. Bs.As., Libera, 1975,2 ed.

NIDO, Enrique. Informe general del movimiento anarquista en la Argentina. Bs. As., La Prolesla, 1923. 
ODDONE. Jacinto. Gremialismo proletario argentino. Bs.As., La Vanguardia, 1947.

OVED, Iaacov. El anarquismo y el movimiento obrero en Argentina. México, Siglo XXI, 1978.

PAN, Luis. Juan B. Justo y la fundación del partido socialista. La Vanguardia, 1956.

PANETTIERI, José. Los trabajadores en tiempos de la inmigración masiva en Argentina 1870-1910. La Plata, Univ. de La Plata, 1965.

PASO, Leonardo. La clase obrera y el nacimiento del marxismo en Argentina. Selección de artículos de Germán Ave Lallemant. Bs.As., Anteo. 1974.

QUESADA. F. El primer anarquista fusilado en Argentina. Bs.As., Destellos S.R.L., 1974.

RATZER, José. Los maraistas argentinos del 90. Córdoba, Pasado y Presente, 1969.

RAMA, Carlos, Los periódicos italianos en América Latina. Montevideo, Nuestro Tiempo, 1968.

ROUCO BUELA, Juana. Historia de un ideal por una mujer. Bs.As., Reconstruir, 1964.

RIVERA DIAZ. Laureano. Memorias de un luchador social, Bs.As., 1979.

SANGUINETTI, Horacio. Los socialistas independientes. Bs.As., ed. Belgrano, 1981.

SOLOMONOF, Jorge. Jdeologías movimiento obrero y conflicto social. Bs.As., Proyección, 1971.

SPALDING, Hobart, La clase trabajadora argentina: Documentos para su historia 1890-1912. Bs.As., Galerna, 1970.

\section{Artículos}

BRAVO, Mario. "Organización, programa y desarrollo del partido socialista en Argentina", en Revista Argentina de Ciencias Políticas, vol.X, 1951.

CORVIERI, Emilio J. "La fundación del partido comunista" en Todo es Historia N 106, Bs.As., 1976.

"Socialistas y anarquistas" en Polémica n 42, 1971.

CUNEO, Dardo. "Un periódico socialistas en $1879 "$ en Revista Socialista año VIII $\quad N^{\circ} 88$, setiembre, 1937.

Bs.As., 1957.

"Las dos corrientes del movimiento obrero del $90^{\circ}$ en Revista de Historia $\mathrm{N}^{\circ} \mathrm{I}$,

CHIINELIJ, Delia; GALMARINI, Hugo R. "Una conspiración comunista en $1875^{\circ}$ en Todo es Historia, N" 102, noviembre, 1975 .

ERMOLAIEV, V. "Naissance du mouvement ouvrier" en Recherches Internationales à la lumière du marxisme, $\mathrm{N}^{\bullet} 32$, juillet-aôùt, 1962.

FALCON, Ricardo "Lucha de tendencias en los primeros congresos del partidoObrero Socialista Argentino, 1896-1900" en Apuntes, octubre-diciembre, 1979.

GONZALO, Fernando. "La prehistoria del anarquismo en América" París, $\mathrm{N}^{\circ} 2,15$ de diciembre de 1924.

GREI A, Plácido. "El movimiento obrero en Rosario" en Todo es Historia n.49, Bs.As., 1971.

KLIMA, Juan. "La Asociación Bonaerense Vorwärts en los años ochenta del siglo pasado" en Ibero-américa Pragensia, año VIII, 1974.

KUHN, AUGUSTO. "Apuntes para la historia del movimiento obrero socialista en la República Argentina" en Nuevos Tiempos, Bs. As., N 5, Julio, 1916.

Bs.As., 1918.

"El movimiento obrero y socialista" en Almanaque del Trabajo para el año 1918,

NETLAU, Max. "La Internacional en Buenos Aires en 1872-1873" en La Protesta Suplemento Semanal, noviembre, 1926.

-"Más sobre la Internacional en Buenos Aires, algunas noticias de los años 1870-1873" en Suplemento quincenal de La Protesta, N²76, enero, 1928.

"Más sobre los orígenes de la Internacional en Buenos Aires.Documentos nuevos e inéditos" en Suplemento quincenal de La Protesta, N²91, setiembre, 1928.

SEGALL, Marcelo. "En Amerique Latine. Développement du mouvement ouvrier et proscription" en International Review of Social History, $N^{\circ} 17,1972$.

VALADES, José. "Documentos para la historia del anarquismo en América" en Certamen Internacional La Protesta, Bs.As., 1927.

WALTER, Richard J. "The socialist press in turn-of-the century Argentina" en The Americas A quaterly review of inter-american Cultural History, Academy of American Franciscan History, vol. XXXVII, julio, 1980. 
Protesta, Bs.As., 1927.

WALTER, Richard J. "The socialist press in turn-of-the century Argentina" en The Americas A quaterly review of inter-american Cultural History, Academy of American Franciscan History, vol. XXXVII, julio, 1980.

ZARAGOZA RUVIRA, Gonzalo. "Errico Malatesta y el anarquismo argentino" en Historiografía y Bibliografia Americanista, vol.XIV, No 3, 1972.

\section{Publicaciones Periódicas}

- ABC del Socialismo. Periódico semanal de propaganda popular. (1890-1900).

- Acción Obrera (La). 1910-1916.

- Acción Socialista (La). 1905-1910.

- Almanaque del trabajo. 1918.

- Anarguía (La). La Plata, 1896.

- Autonomía Individual (La). Buenos Aires, 1897.

- Bandera Roja.

- Caras y Caretas, Buenos Aires.

- Carpintero (El). Rosario, 1896.

- Caserio. Buenos Aires, 1896.

- Correspondencia (La). Buenos Aires, 1875.

- Casmopolita (El). Buenos Aires, 1879-1880.

- Cyclone (Le). Buenos Aires, 1895-1896.

- Demoliamo. Rosario, 1893.

- Escalpelo (EI). Buenos Aires, 1899.

- Eco del rebelde (El). Zaragoza, 1895.

- Español (El). Buenos Aires, 1875.

- Federación (La). Barcelona, 1870.

- Germinal. Buenos Aires, 1897-1899.

- Ideas y Figuras. Buenos Aires, 1909-1911.

- Internacional (La).

- Il Libertario. La Spezia.

- Il Risvegiio. Córdoba, 1887.

- Il Sacialista. Buenos Aires, 1896-1897.

- L'Allianza Libertaria, Roma.

- L'Ámico del Popolo. "Monitore della sociesá Republicana al Plata" 1896-1912.

- L'Avvenire. Buenos Aires, 1895-1904.

- Lavoriamo. 1893.

- Liberté (La). Buenos Aires, 1893-1894.

- Luz (La). Buenos Aires, 1878.

- Miseria (La). Buenos Aires, 1890.

- Montaña (La). 1897.

- Nueva Civilitá (La). Buenos Aires, 1901.

- Nueva humanidad (La). Rosario, 1899.

- Obrero (El). Buenos Aires, 1892.

- Obrero (El). Diamante, 1889.

- Obrero Ferroviario (El). 1912-1920.

- Obrero Gráfico (El). Buenos Aires, 1914.

- Obrero Tipógrafo (El). Buenos Aires, 1872.

- Obrero Panadero (EI). Buenos Aires.

- Oprimido (El), Luján, 1894-1896.

- Organización (La). 1901.

- Organización obrera (La). Buenos Aires, 1901-1916.

- Patria Italiana (La). Buenos Aires,1887. 
- Perseguido (El). Buenos Aires, 1890-1897.

- Productor (El). Barcelona, 1887.

- Protesta Humana (La). Buenos Aires, 1897-1902.

- Protesta (La). Buenos Aires, 1903.

- Questione Sociale (La). Buenos Aires, 1894-1896.

- Rebelde (El). Buenos Aires, 1899-1901.

- Redención.

- Revista de Filosofía.

- Revista Internacional Anarquista (La).

- Revista Socialista. Buenos Aires.

- Revolución Social (La). Buenos Aires, 1896-1897.

- Riscossa (La). Buenos Aires, 1893.

- Socialista (El). Buenos Aires, 1882.

- Sol (Ei). Buenos Aires, 1900-1903.

- Solidaridad. Rosario, 1902.

- Solidaridad (La). Sevilla, 1889.

- Unión Gremial (La). Buenos Aires, 1895.

- Unión Obrera (La). 1905-1909.

- Vanguardia (La). 1894.

- Verdad (La). Rosario, 1895.

- Vonwärst. Buenos Aires, 1886-1896.

- Voz del Esclavo (La). Chivilcoy, 1902.

- Voz de la mujer (La). Buenos Aires, 1896.

- Voz de Ravachol (La). Buenos Aires, 1895. 